\title{
Parametric study on thermal and hydraulic characteristics of laminar flow in microchannel heat sink with fan-shaped ribs on sidewalls - Part 3: performance evaluation
}

Lei Chai ${ }^{\mathrm{a},}$, , Guo Dong Xia ${ }^{\mathrm{b}}$, Hua Sheng Wang ${ }^{\mathrm{a}}$

${ }^{\text {a }}$ School of Engineering and Materials Science, Queen Mary University of London, Mile End Road, London E1 4NS, UK

${ }^{\mathrm{b}}$ Key Laboratory of Enhanced Heat Transfer and Energy Conservation, Ministry of Education, College of Environmental and Energy Engineering, Beijing University of Technology, Beijing, China

\begin{abstract}
In order to comprehensively assess the performance of microchannel heat sink with fan-shaped ribs on sidewalls, this third part of a three-part study focuses on the relationship between thermal resistance and pumping power, and further the entropy generation rate and performance evaluation criteria, with water and silicon used as fluid and solid for the computational domain. The microchannel has the width of $0.1 \mathrm{~mm}$ and depth of $0.2 \mathrm{~mm}$ in the constant cross-section region. The geometric parameters include the width (0.005-0.4 mm), height $(0.005-0.025 \mathrm{~mm})$ and spacing $(0.2-5 \mathrm{~mm})$ of aligned or offset fan-shaped ribs. For deep insight into the basic mechanisms and properties of such heat sinks, the entropy generation rate due to heat transfer and fluid friction are separately studied. Results show that the fan-shaped ribs can lead to better comprehensive performance and the geometric parameters of fan-shaped ribs have a significant influence on the performance of such microchannel heat sinks. With the increase of the rib's height, the microchannel heat
\end{abstract}

\footnotetext{
${ }^{*}$ Corresponding author. Tel.: +44 2078827306.

E-mail address: 1.chai@qmul.ac.uk (Lei Chai).
} 
sinks with offset fan-shaped ribs gradually perform better than the ones with aligned fan-shaped ribs. With the decrease of the rib's spacing, the comprehensive performance firstly becomes better and then gradually deteriorates. For the microchannel heat sink with large rib's height and small rib's spacing, the increase of Reynolds number can lead to tremendously increase of entropy generation rate due to fluid friction, which can withdraw the decrease of entropy generation rate due to heat transfer and lead to the increase of total entropy generation rate, making the comprehensive performance worse than the smooth one. For Reynolds number ranging from 187 to 715 and studied geometric parameters, the best microchannel heat sink shows a $32 \%$ decrease in entropy generation rate and 1.33 in performance evaluation criterion, comparing with the smooth one.

Key words microchannel heat sink; fan-shaped ribs; entropy generation rate; performance evaluation criterion

\section{Introduction}

With the development of microelectromechanical devices, the microchannel heat sink has been successfully used for heat removal in a variety of devices, such as micropumps, microvalves, and microsensors. Further, the higher volumetric heat transfer densities require advanced manufacturing techniques and lead to more complex manifold designs. Recently, a significant amount of research work has been developed as innovative cooling techniques those have the potential to deliver high-heat flux rates for microelectronic applications [1]. Xu et al. [2, 3] used the thermal boundary layer redeveloping concept to demonstrate the 
interrupted microchannel heat sink to improve the heat transfer performance. Chai et al. [4, 5] took advantage of the interruption of boundary layer formation and establishment of secondary flow to develop the microchannel heat sinks with periodic expansion-constriction cross-sections. Cheng [6], Hong and Cheng [7] and Foong et al. [8] based on the enhanced mixing mechanism of cold and hot fluids to introduce the passive microstructures into the microchannels. Combining the advantages of interrupted microchannel and passive microstructures, Chai et al. [9] introduced the staggered rectangular ribs into the transverse microchambers for better heat transfer performance.

However, employing microchannel heat sink usually results in a higher pressure drop per unit length, although with higher heat transfer performance. Therefore, the application of microchannels to electronics cooling imposes severe design constraints on the system design. For a given heat dissipation rate, the flow rate, pressure drop, fluid temperature rise, and fluid inlet to surface temperature difference requirements necessitate optimization of the channel geometry [10]. For the optimization design of microchannel heat sink, several experimental, numerical and theoretical studies on the optimization of microchannel heat sinks have been conducted. Tsai and Reiyu [11] and Liu and Garimella [12] established theoretical optimization models based on thermal resistance minimization for a given pumping power to predict microchannel heat sink performance. Singhal et al. [13], Kandlikar and Upadhye [14], Gosselin and Bejan [15], and Canhoto and Reis [16] carried out optimization methods based on the minimization of pumping power requirement for a given thermal resistance to evaluate the heat transfer performance. For further study the optimization of thermal and hydraulic resistances simultaneously with all relevant design parameters for microchannel heat sinks 
including geometric parameters, material properties and flow conditions, Xie et al. [17] used the relationship between the thermal resistance and the pumping power to evaluate the heat transfer enhancement performance of the microchannel heat sinks with internal vertical Y-shaped bifurcations. Famouri et al. [18] and Shi and Dong [19] applied optimization methods based on entropy generation minimization for the optimization of a variable-height shrouded fin array and microchannel with staggered arrays of pin fin structure, respectively. Promvonge et al. [20], Xia et al. [21, 22], Chai et al. [9], and Zhang et al. [23] used the performance evaluation criteria to comprehensively access the heat transfer enhancement performance of microchannel heat sinks with passive microstructures.

In the first and second parts of this three-part study, three-dimensional numerical models have been carried out to examine the laminar flow and heat transfer characteristics in the microchannel heat sink with fan-shaped ribs on sidewalls. To study the effects of geometric parameters of fan-shaped ribs on thermal and hydraulic characteristics, three non-dimensional variables have been designed, respectively representing the width, height and spacing of aligned and offset fan-shaped ribs. In order to comprehensively assess the performance of such microchannel heat sink, this part of the study is to focus on the relationship between thermal resistance and pumping power, entropy generation rate and performance evaluation criteria for laminar flow in such microchannel heat sink with the purpose of optimum channel geometric configuration.

\section{Model formulation and solution methodology}

Figure 1a illustrates schematic of the enhanced microchannel heat sink, which also used as the computational domain. In this design, the fan-shaped ribs are mounted on the two 
parallel sidewalls in tandem for both aligned and offset arrangements. The computational domain has the length of $10 \mathrm{~mm}$, width of $0.25 \mathrm{~mm}$, and height of $0.35 \mathrm{~mm}$. The microchannel has the length of $10 \mathrm{~mm}$ and the depth of $0.2 \mathrm{~mm}$, respectively. The width of the two parallel sidewalls for microchannel without ribs $\left(W_{\mathrm{c}}\right)$ is $0.1 \mathrm{~mm}$. The geometric parameters of fan-shaped ribs studied in this paper are shown in Fig. 1b, including the width $\left(W_{\mathrm{r}}\right)$, the height $\left(H_{\mathrm{r}}\right)$, and the spacing $\left(S_{\mathrm{r}}\right)$. The ranges for these geometric parameters examined in this paper are 0.005-0.4 mm for $W_{\mathrm{r}}, 0.005-0.025 \mathrm{~mm}$ for $H_{\mathrm{r}}$, and 0.2-5 $\mathrm{mm}$ for $S_{\mathrm{r}}$. Three non-dimensional variables are designed to analyze their effects on thermal and hydraulic characteristics, including the ratio of the width of rib to the spacing $\left(W_{\mathrm{r}} / S_{\mathrm{r}}\right)$, the ratio of the height of rib to the width of the two parallel sidewalls $\left(H_{\mathrm{r}} / W_{\mathrm{c}}\right)$, and the ratio of the spacing of ribs to the width of the two parallel sidewalls $\left(S_{\mathrm{r}} / W_{\mathrm{c}}\right)$, respectively.

The simulations are performed using the ANSYS FLUENT 12.0 software. The SIMPLEC algorithm is applied to solve the governing differential equations for the velocity, pressure and temperature fields in the microchannels. These governing equations are listed as follows:

$\frac{\partial}{\partial x_{i}}\left(\rho u_{i}\right)=0$

$\frac{\partial}{\partial x_{i}}\left(\rho_{\mathrm{f}} u_{i} u_{j}\right)=-\frac{\partial p}{\partial x_{j}}+\frac{\partial}{\partial x_{i}}\left[\mu_{\mathrm{f}}\left(\frac{\partial u_{j}}{\partial x_{i}}+\frac{\partial u_{i}}{\partial x_{j}}\right)\right]$

$\frac{\partial}{\partial x_{i}}\left(\rho_{\mathrm{f}} u_{i} c_{\mathrm{pf}} T\right)=\frac{\partial}{\partial x_{i}}\left(k_{\mathrm{f}} \frac{\partial T}{\partial x_{i}}\right)+\mu_{\mathrm{f}}\left[2\left(\frac{\partial u_{i}}{\partial x_{i}}\right)^{2}+\left(\frac{\partial u_{j}}{\partial x_{i}}+\frac{\partial u_{i}}{\partial x_{j}}\right)^{2}\right]$

For the solid

$\frac{\partial}{\partial x_{i}}\left(k_{\mathrm{s}} \frac{\partial T}{\partial x_{i}}\right)=0$

where $\rho$ is density, $\mu$ is dynamic viscosity, $c_{\mathrm{p}}$ is specific heat capacity, $k$ is thermal 
conductivity, $x_{1}, x_{2}$ and $x_{3}$ are $x, y$ and $z$ coordinates, respectively, as shown in Fig. 1a. Subscripts $f$ and s refer to fluid and solid, respectively.

At the channel inlet and outlet, the velocity-inlet and pressure-outlet boundaries are applied. The solid part of the heat sink corresponding to the inlet and outlet of the channel is maintained as an adiabatic boundary. At the interior walls of the channel, no-slip and no-penetration boundary conditions are applied. At the base of heat sink, constant heat flux boundary condition is used. At the top surface of the computational domain including solid and fluid, an adiabatic boundary is assumed. Due to symmetry of the problem, symmetry boundary is maintained at the two sides of the computational domain. The parameters used in this study are in the following ranges: the velocity-inlet $u_{\text {in }}$ are selected as the average velocity in the constant cross-section region $\bar{u}=1,2,3,4$ and $5 \mathrm{~m} \cdot \mathrm{s}^{-1}$, the temperature at the channel inlet $T_{\text {in }}=293 \mathrm{~K}$, the pressure at the channel outlet $p_{\text {out }}=0$ (gauge pressure) and constant heat flux at the heat sink base $q_{\mathrm{w}}=10^{6} \mathrm{~W} \cdot \mathrm{m}^{-2}$. The fluid and solid are water and silicon, respectively. The thermo-physical properties of water including $\rho_{\mathrm{f}}, \mu_{\mathrm{f}}, c_{\mathrm{pf}}$ and $k_{\mathrm{f}}$ depend on temperatures in accordance to Incropera [24]. The thermal conductivity of silicon $k_{\mathrm{s}}$ is set as a constant of $148 \mathrm{~W} \cdot \mathrm{m}^{-1} \mathrm{~K}^{-1}$ in the computations.

The solutions are considered to be converged when the normalized residual values are less than $10^{-5}$ for all the variables. For every microchannel heat sink, a grid independence test is conducted using several different mesh sizes. The grid independence test and the physical model validation test are similar to Chai et al. [25].

\section{Data acquisition}


Loosen [26] proposed a simplified one-dimensional analytical model to study the thermal resistance. The total thermal resistance of microchannel heat sink is defined as

$$
R_{\mathrm{th}}=\frac{\overline{T_{\mathrm{w}}}-T_{\mathrm{in}}}{q_{\mathrm{w}} L W}
$$

where $q_{\mathrm{w}}$ is the heat flux at the silicon base, $L$ and $W$ are respectively the length and width of silicon base, $T_{\text {in }}$ is the water temperature in the channel inlet, $\overline{T_{\mathrm{w}}}$ is the area-weighted temperature of the silicon base and defined as

$$
\overline{T_{\mathrm{w}}}=\frac{\int T_{\mathrm{w}, \mathrm{x}, \mathrm{y}} d y d x}{\int d y d x}
$$

The pumping power are defined as

$$
P_{\mathrm{p}}=\Delta p_{\text {mic }} \stackrel{g}{V}
$$

where $\stackrel{g}{V}$ is the fluid volume flow rate, $\Delta p_{\text {mic }}$ is the pressure drop of the microchannel $\left(\Delta p_{\text {mic }}=\right.$ $\left.p_{\text {in }}-p_{\text {out }}\right), p_{\text {in }}$ is the mass-weighted average pressure and defined as

$$
p_{\mathrm{in}}=\frac{\int p_{\mathrm{in}, \mathrm{i}} \rho_{\mathrm{f}, \mathrm{i}}|\stackrel{\mathrm{r}}{u} \cdot \stackrel{\mathrm{r}}{\mathrm{r}} \cdot d A|}{\int \rho_{\mathrm{f}, \mathrm{i}}|u \cdot d A|}
$$

Khan et al. [27] proposed an entropy generation minimization procedure to optimize the overall performance of microchannel heat sinks. This procedure allowed the combined effect of thermal resistance and pressure drop to be assessed simultaneously as the heat sink interacts with the surrounding flow field.

$$
S_{\text {gen }}=S_{\text {gen, } \mathrm{h}}+S_{\text {gen, }}=\frac{Q\left(\overline{T_{\mathrm{w}}}-T_{\mathrm{a}}\right)}{\overline{T_{\mathrm{w}}} T_{\mathrm{a}}}+\frac{\stackrel{\mathrm{g}}{m}\left(p_{\mathrm{in}}-p_{\text {out }}\right)}{\rho_{\mathrm{f}} T_{\mathrm{a}}}
$$

where $Q$ is the heat transfer rate, $\rho_{\mathrm{f}}$ is the volume average fluid density, $T_{\mathrm{a}}$ is the ambient temperature and assumed to $T_{\mathrm{a}}=T_{\mathrm{in}}, \stackrel{\mathrm{g}}{m}$ is the fluid mass flow rate, $S_{\text {gen }}$ is the total entropy generation rate, and $S_{\mathrm{genh \textrm {h }}}$ and $S_{\mathrm{gen}, \mathrm{f}}$ are the entropy generation rates due to heat transfer and 
fluid friction, respectively.

In order to access the enhanced heat transfer surfaces in heat exchanger design, Webb [28] outlined detailed procedures to calculate the performance improvement and to select the optimum surface geometry. For the microchannel heat sink with offset ribs on sidewalls, the performance evaluation criteria $(P E C)$ is defined as the ratio of the heat transfer coefficient $(\bar{h})$ to the smooth microchannel heat sink $\left(\bar{h}_{0}\right)$ at an equal pumping power. For a constant pumping power,

$(\dot{V} \Delta p)_{0}=(\dot{V} \Delta p)$

The relationship between the average friction factor and Reynolds number can be expressed as

$$
\begin{aligned}
& f_{\text {ave }, 0} R e_{0}^{3}=f_{\text {ave }} R e^{3} \\
& R e_{0}=\operatorname{Re}\left(f_{\text {ave }} / f_{\text {ave }, 0}\right)^{1 / 3}
\end{aligned}
$$

Therefore, the $P E C$ is given by

$$
P E C=\left.\frac{\bar{h}}{\bar{h}_{0}}\right|_{\mathrm{pp}}=\left.\frac{\overline{N u}}{\overline{N u}}\right|_{\mathrm{pp}}=\frac{\overline{N u} / \overline{N u}_{0}}{\left(\bar{f} / \bar{f}_{0}\right)^{1 / 3}}
$$

where $\overline{N u}_{0}$ and $\bar{f}_{0}$ respectively stand for Nusselt number and friction factor of the smooth microchannel heat sink. The average Fanning friction factor is given by

$$
\bar{f}=\frac{\left(p_{\text {in }}-p_{\text {out }}\right) D_{\mathrm{h}}}{2 \rho_{\mathrm{f}} L \bar{u}}
$$

where $D_{\mathrm{h}}$ is the hydraulic diameter calculated based on the constant cross-section region. The average heat transfer coefficient and Nusselt number are given by

$$
\bar{h}=\frac{q_{\mathrm{w}} L W}{A\left(\overline{T_{\mathrm{w}}}-\overline{T_{\mathrm{f}}}\right)}
$$


$\overline{N u}=\frac{\bar{h} D_{\mathrm{h}}}{k_{\mathrm{f}}}$

where $A$ is the inner wall/ fluid contact surface area based on the smooth microchannel, $k_{\mathrm{f}}$ is the mass-average fluid thermal conductivity. The Reynolds number are defined as $R e=\frac{\rho_{\mathrm{f}} \bar{u} D_{\mathrm{h}}}{\mu_{\mathrm{f}}}$

where $\mu_{\mathrm{f}}$ is the mass-average fluid dynamic viscosity.

\section{Results and discussion}

\subsection{Thermal resistance and pumping power}

Figure 2 shows the effect of $W_{\mathrm{r}} / S_{\mathrm{r}}$ on the relationship between $R_{\mathrm{th}}$ and $P_{\mathrm{p}}$ with $R e=187$, $316,443,582$ and 715 . The solid black line is for the smooth microchannel heat sink (MCHS). The geometry of fan-shaped ribs used in this figure is $W_{\mathrm{c}}=0.1 \mathrm{~mm}, H_{\mathrm{r}}=0.025 \mathrm{~mm}, S_{\mathrm{r}}=0.4$ $\mathrm{mm}$ and $W_{\mathrm{r}}=0.1,0.2,0.3$ and $0.4 \mathrm{~mm}$. It is noticed that the $R_{\mathrm{th}}$ drops quickly with increase of $P_{\mathrm{p}}$ for all the microchannel heat sinks, due to the increase of heat transfer coefficient and the decrease of average fluid temperature with increase of $P_{\mathrm{p}}$ [4]. It can be observed that the microchannel heat sink with fan-shaped ribs leads to lower $R_{\mathrm{th}}$ at the same $P_{\mathrm{p}}$, indicating the better comprehensive performance. For $W_{\mathrm{r}} / S_{\mathrm{r}}=0.25$ and 0.5 , the microchannel heat sink with offset fan-shaped ribs (MCHS-OFR) has obviously better performance than the one with aligned fan-shaped ribs (MCHS-AFR), while for $W_{\mathrm{r}} / S_{\mathrm{r}}=0.75$ and 1 , the MCHS-OFR shows just a little better than MCHS-AFR.

Figure 3 shows the effect of $H_{\mathrm{r}} / W_{\mathrm{c}}$ on the relationship between $R_{\mathrm{th}}$ and $P_{\mathrm{p}}$ with $R e=187$, $316,443,582$ and 715 . The geometry of fan-shaped ribs used in this figure is $W_{\mathrm{c}}=0.1 \mathrm{~mm}, S_{\mathrm{r}}$ $=0.4 \mathrm{~mm}, W_{\mathrm{r}}=0.1 \mathrm{~mm}$ and $H_{\mathrm{r}}=0.005,0.015$ and $0.025 \mathrm{~mm}$. It can be found that the 
MCHS-OFR with $H_{\mathrm{r}} / W_{\mathrm{c}}=0.15$ shows much better performance than that with $H_{\mathrm{r}} / W_{\mathrm{c}}=0.05$, and just a little worse than that with $H_{\mathrm{r}} / W_{\mathrm{c}}=0.25$; The MCHS-AFR with $H_{\mathrm{r}} / W_{\mathrm{c}}=0.15$ shows the better heat transfer performance than those with $H_{\mathrm{r}} / W_{\mathrm{c}}=0.05$ and 0.25 . It is also noted that the MCHS-AFR has better performance than MCHS-OFR for $H_{\mathrm{r}} / W_{\mathrm{c}}=0.05$, while the contrary tendency for $H_{\mathrm{r}} / W_{\mathrm{c}}=0.15$ and 0.25 . It is also seen that with the increase of $H_{\mathrm{r}}$, the $P_{\mathrm{p}}$ extremely increases for MCHS-AFR due to the large increase of pressure drop.

Figure 4 shows the effect of $S_{\mathrm{r}} / W_{\mathrm{c}}$ on the relationship between $R_{\mathrm{th}}$ and $P_{\mathrm{p}}$ with $R e=187$, $316,443,582$ and 715 . The geometry of fan-shaped ribs used in this figure is $W_{\mathrm{c}}=0.1 \mathrm{~mm}$, $W_{\mathrm{r}}=0.1 \mathrm{~mm}, H_{\mathrm{r}}=0.025 \mathrm{~mm}$ and $S_{\mathrm{r}}=0.25,0.5,1$ and $2 \mathrm{~mm}$. It is noted that the MCHS-AFR with $S_{\mathrm{r}} / W_{\mathrm{c}}=10$ and 5 have a little better performance than those with $S_{\mathrm{r}} / W_{\mathrm{c}}=20$ and 2.5 , while the MCHS-OFR with $S_{\mathrm{r}} / W_{\mathrm{c}}=5$ and 2.5 perform better than those with $S_{\mathrm{r}} / W_{\mathrm{c}}=20$ and 10, suggesting that there are a range of $S_{\mathrm{r}}$ for better performance. From Figs. 2, 3 and 4, it also can be observed that the relationship between $R_{\mathrm{th}}$ and $P_{\mathrm{p}}$ is not very clear to present the comprehensive thermal performance if the heat sink has many changed geometric parameters, because the $R_{\mathrm{th}}$ and $P_{\mathrm{p}}$ separately present the performance of heat transfer and pressure drop.

\subsection{Entropy generation rate}

Figures 5a, 5b and 5c respectively show the effects of $W_{\mathrm{r}} / S_{\mathrm{r}}$ on $S_{\text {gen, }}, S_{\text {gen,h }}$ and $S_{\text {gen,f }}$ with $R e=187,316,443,582$ and 715 . The geometry of fan-shaped ribs used in these figures is the same as Fig. 2. It can be noted that the fan-shaped ribs can result in lower $S_{\text {gen }}$ and $S_{\text {gen,h, }}$, but higher $S_{\text {gen,f. From Fig. }} 5 \mathrm{~b}$, it is noticed that the increase of $R e$ leads to obvious decreases of

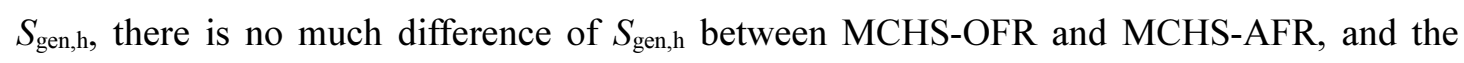


$W_{\mathrm{r}} / S_{\mathrm{r}}$ does not have obvious influence on $S_{\mathrm{gen}, \mathrm{h}}$. From Fig. $5 \mathrm{c}$, it can be seen that the quantity of $S_{\text {gen,f }}$ is largely lower than $S_{\text {gen,h, }}$, but tremendously increases with increase of $R e$, and the increase rate is much higher than MCHS, further the MCHS-AFR shows larger increase rate than MCHS-OFR. With the increase of $R e$, the $S_{\text {gen,f }}$ can have an significant influence on $S_{\text {gen }}$. The increase of $W_{\mathrm{r}} / S_{\mathrm{r}}$ and $R e$ leads to much larger $S_{\mathrm{gen}, \mathrm{f}}$, which can withdraw the deceased $S_{\mathrm{gen,h}}$ and result in deterioration of such heat sink performance. As shown in Fig. 5a, under the influence of both $S_{\mathrm{gen}, \mathrm{h}}$ and $S_{\mathrm{gen}, \mathrm{f}}$, the $S_{\mathrm{gen}}$ decreases with increase of $R e$ as $R e<443$, while the decrease rate becomes lower or even minus with increase of $R e$ as $R e>443$.

Figures $6 \mathrm{a}, 6 \mathrm{~b}$ and $6 \mathrm{c}$ respectively show the effect of $H_{\mathrm{r}} / W_{\mathrm{c}}$ on $S_{\mathrm{gen}}, S_{\mathrm{gen}, \mathrm{h}}$ and $S_{\mathrm{gen}, \mathrm{f}}$ with $R e=187,316,443,582$ and 715 . The geometry of fan-shaped ribs used in these figures is the same as Fig. 3. From Fig. 6a, it can be seen that the increase of $H_{\mathrm{r}} / W_{\mathrm{c}}$ leads to large decrease of $S_{\text {gen, }}$ except the MCHS-AFR with $H_{\mathrm{r}} / W_{\mathrm{c}}=0.25$ as $R e>582$. As $H_{\mathrm{r}} / W_{\mathrm{c}}=0.05$ and $0.15, S_{\text {gen }}$ of MCHS-AFR is a litter lower than MCHS-OFR, while as $H_{\mathrm{r}} / W_{\mathrm{c}}=0.25$, they show almost the same $S_{\text {gen }}$ as $R e<443$ and the MCHS-AFR is evidently larger than MCHS-OFR as $R e>$ 443. From Figs. $6 \mathrm{~b}$ and $6 \mathrm{c}$, it can be seen that the increase of $H_{\mathrm{r}} / W_{\mathrm{c}}$ results in large decrease of $S_{\mathrm{genh}}$ and extreme increase of $S_{\mathrm{gen}, \mathrm{f}}$ for both MCHS-AFR and MCHS-OFR. Further with the increase of $H_{\mathrm{r}} / W_{\mathrm{c}}$, the MCHS-AFR shows almost the same $S_{\mathrm{gen}, \mathrm{h}}$ but much higher $S_{\mathrm{gen, \textrm {f }}}$ than MCHS-OFR. Especially for MCHS-AFR with $H_{\mathrm{r}} / W_{\mathrm{c}}=0.25$ as $R e>582$, the increase of $S_{\text {gen,f }}$ withdraws the decrease of $S_{\text {gen,h, }}$ leading to the increase of $S_{\text {gen }}$ with $R e$ as shown in Fig. 6a.

Figures 7a, 7b and 7c respectively show the effect of $S_{\mathrm{r}} / W_{\mathrm{c}}$ on $S_{\mathrm{gen}}, S_{\mathrm{gen}, \mathrm{h}}$ and $S_{\text {gen,f }}$ with $R e=187,316,443,582$ and 715 . The geometry of fan-shaped ribs used in these figures is the same as Fig. 4. From Fig. 7a, it can be seen that the decrease of $S_{\mathrm{r}} / W_{\mathrm{c}}$ generally leads to 
decrease of $S_{\text {gen }}$, except the MCHS-AFR with $S_{\mathrm{r}} / W_{\mathrm{c}}=5$ and 2.5 as $R e>443$ and MCHS-OFR with $S_{\mathrm{r}} / W_{\mathrm{c}}=2.5$ as $R e>582$. From Fig. $7 \mathrm{~b}$, it can be found that the decrease of $S_{\mathrm{r}} / W_{\mathrm{c}}$ generally leads to obvious decrease of $S_{\mathrm{gen}, \mathrm{h}}$ and there is no much difference of $S_{\mathrm{genh \textrm {h }}}$ between MCHS-AFR and MCHS-OFR. From Fig. 7c, it is noticed that with the increase of Re, the increase of $S_{\mathrm{r}} / W_{\mathrm{c}}$ results in extreme increase of $S_{\mathrm{gen}, \mathrm{f}}$, and the MCHS-AFR shows higher $S_{\mathrm{gen}, \mathrm{f}}$ than MCHS-OFR. As shown in Fig. 7a, the MCHS-AFR with $S_{\mathrm{r}} / W_{\mathrm{c}}=5$ and 2.5 as $R e>443$ and MCHS-OFR with $S_{\mathrm{r}} / W_{\mathrm{c}}=2.5$ as $R e>582$, the increase of $S_{\mathrm{gen}, \mathrm{f}}$ withdraws the decrease of

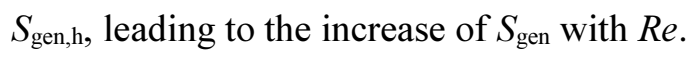

To further investigate the influence of the channel geometric configuration on entropy generation rate, Fig. 8a shows the effects of $W_{\mathrm{r}} / S_{\mathrm{r}}$ and $R e$ on the entropy generation rate ratio to the MCHS $\left(S_{\text {gen }} / S_{\text {gen, }, 0}\right)$, and Fig. $8 \mathrm{~b}$ shows the effects of $W_{\mathrm{r}} / S_{\mathrm{r}}$ and Re on the entropy generation rate ratio due to heat transfer $\left(S_{\mathrm{gen}, \mathrm{h}} / S_{\mathrm{gen}}\right)$. The geometry of fan-shaped ribs used in these figures is $W_{\mathrm{c}}=0.1 \mathrm{~mm}, H_{\mathrm{r}}=0.025 \mathrm{~mm}, S_{\mathrm{r}}=0.4 \mathrm{~mm}$ and $W_{\mathrm{r}}=0.05-0.4 \mathrm{~mm}$. From Fig. $8 \mathrm{a}$, it can be seen that there is no very clear relationship between $W_{\mathrm{r}} / S_{\mathrm{r}}$ and $S_{\text {gen }} / S_{\text {gen, } 0}$. For MCHS-AFR, the $S_{\text {gen }} / S_{\text {gen, } 0}$ for $R e=187$ and 316 generally decreases with $W_{\mathrm{r}} / S_{\mathrm{r}}$ as $W_{\mathrm{r}} / S_{\mathrm{r}}>0.4$, and that for $R e=582$ and 715 firstly rapidly decreases as $W_{\mathrm{r}} / S_{\mathrm{r}}<0.3$ and then increases slowly. For MCHS-OFR, the $S_{\text {gen }} / S_{\text {gen, } 0}$ for $R e=187$ generally decreases with $W_{\mathrm{r}} / S_{\mathrm{r}}$ as $W_{\mathrm{r}} / S_{\mathrm{r}}>$ 0.5 , and the ones for $R e=582$ and 715 decrease with increase of $W_{\mathrm{r}} / S_{\mathrm{r}}$ as $W_{\mathrm{r}} / S_{\mathrm{r}}<0.3$ and then increase as $W_{\mathrm{r}} / S_{\mathrm{r}}>0.3$. With the increase of $W_{\mathrm{r}} / S_{\mathrm{r}}$ from 0.125 to 1 , the $S_{\text {gen }} / S_{\text {gen, } 0}$ for MCHS-AFR changes in the ranges of 0.74-0.82, 0.7-0.75, 0.71-0.74, 0.75-0.82 and 0.85-0.96 respectively for $R e=187,316,443,582$ and 715 , and the $S_{\text {gen }} / S_{\text {gen, } 0}$ for MCHS-OFR changes in the ranges of $0.77-0.82,0.69-0.75,0.67-0.75,0.7-0.81$ and $0.75-0.9$ respectively for $R e=$ 
187, 316, 443, 582 and 715. From Fig. 8b, it can be seen that the increase of Re results in large decrease of $S_{\mathrm{gen,h}} / S_{\mathrm{gen}}$, and with the increase of $R e$, the MCHS-AFR shows much lower $S_{\text {gen,h }} / S_{\text {gen }}$ than MCHS-OFR. As $R e=187,316$ and 443 , the $S_{\text {gen,h }} / S_{\text {gen }}$ shows little variation with increase of $W_{\mathrm{r}} / S_{\mathrm{r}}$; As $R e=582$ and 715 , the $S_{\text {gen, } \mathrm{h}} / S_{\text {gen }}$ increase with increase of $W_{\mathrm{r}} / S_{\mathrm{r}}$ as $W_{\mathrm{r}} / S_{\mathrm{r}}<0.25$, keeps almost the same in the range from 0.25 to 0.625 , and drops for MCHS-AFR but changes little for MCHS-OFR as $W_{\mathrm{r}} / S_{\mathrm{r}}>0.625$. With the increase of $W_{\mathrm{r}} / S_{\mathrm{r}}$ form 0.125 to 1 , the $S_{\text {gen,h }} / S_{\text {gen }}$ for MCHS-AFR changes in the ranges of $0.994-0.997$, 0.961-0.977, 0.894-0.917, 0.781-0.826 and 0.638-0.689 respectively for $R e=187,316,443$, 582 and 715 , and the $S_{\text {gen,h }} / S_{\text {gen }}$ for MCHS-OFR changes in the ranges of $0.995-0.997$, 0.969-0.984, 0.912-0.949, 0.829-0.889 and 0.731-0.805 respectively for $R e=187,316,443$, 582 and 715.

Figures $9 \mathrm{a}$ and $9 \mathrm{~b}$ show the effects of $H_{\mathrm{r}} / W_{\mathrm{c}}$ and $R e$ on $S_{\mathrm{gen}} / S_{\mathrm{gen}, 0}$ and $S_{\mathrm{gen}, \mathrm{h}} / S_{\mathrm{gen}}$. The geometry of fan-shaped ribs used in these figures is $W_{\mathrm{c}}=0.1 \mathrm{~mm}, S_{\mathrm{r}}=0.4 \mathrm{~mm}, W_{\mathrm{r}}=0.1 \mathrm{~mm}$ and $H_{\mathrm{r}}=0.005-0.025 \mathrm{~mm}$. From Fig. 9a, it can be seen that the increase of $H_{\mathrm{r}} / W_{\mathrm{c}}$ leads to decrease of $S_{\mathrm{gen}} / S_{\mathrm{gen}, 0}$ for lower $\operatorname{Re}(\operatorname{Re}=187,316$ and 443$)$, while first decrease and then increase for larger $\operatorname{Re}(\operatorname{Re}=582$ and 715$)$, and the turning point is earlier for larger $R e$ and MCHS-AFR. With the increase of $H_{\mathrm{r}} / W_{\mathrm{c}}$ form 0.05 to 0.25 , the $S_{\mathrm{gen}} / S_{\text {gen, } 0}$ decreases from 0.947 to $0.823,0.925$ to $0.733,0.918$ to $0.716,0.918$ to 0.719 then 0.761 , and 0.921 to 0.739 then 0.956 for MCHS-AFR respectively at $R e=187,316,443,582$ and 715 ; from 0.957 to $0.813,0.946$ to $0.731,0.947$ to $0.699,0.952$ to $0.699,0.958$ to 0.747 for MCHS-OFR respectively at $R e=187,316,443,582$ and 715 . From Fig. 9b, it is noticed that the increases of $R e$ and $H_{\mathrm{r}} / W_{\mathrm{c}}$ result in large decrease of $S_{\mathrm{gen,h}} / S_{\mathrm{gen}}$, and the decrease rate of $S_{\mathrm{gen,h}} / S_{\text {gen }}$ with 
$R e$ increases with increase of $H_{\mathrm{r}} / W_{\mathrm{c}}$. As $R e=187$, the MCHS-AFR shows almost the same $S_{\text {gen,h }} / S_{\text {gen }}$ with MCHS-OFR, while with the increase of $R e$, the MCHS-AFR shows much lower $S_{\text {gen, } \mathrm{h}} / S_{\text {gen }}$ than MCHS-OFR. With the increase of $H_{\mathrm{r}} / W_{\mathrm{c}}$ from 0.05 to 0.25 , the $S_{\text {gen, } \mathrm{h}} / S_{\text {gen }}$ decreases from 0.999 to $0.997,0.994$ to $0.976,0.982$ to $0.919,0.963$ to 0.825 , and 0.936 to 0.691 for MCHS-AFR respectively at $R e=187,316,443,582$ and 715 ; from 0.999 to 0.998 , 0.994 to $0.984,0.983$ to $0.949,0.965$ to 0.884 , and 0.939 to 0.793 for MCHS-OFR respectively at $R e=187,316,443,582$ and 715 .

Figures 10a and 10b show the effects of $S_{\mathrm{r}} / W_{\mathrm{c}}$ and $R e$ on $S_{\mathrm{gen}} / S_{\mathrm{gen}, 0}$ and $S_{\mathrm{gen}, \mathrm{h}} / S_{\mathrm{gen}}$. The geometry of fan-shaped ribs used in these figures is $W_{\mathrm{c}}=0.1 \mathrm{~mm}, W_{\mathrm{r}}=0.1 \mathrm{~mm}, H_{\mathrm{r}}=0.025$ $\mathrm{mm}$ and $S_{\mathrm{r}}=0.2-5 \mathrm{~mm}$. From Fig. 10a, it can be seen that for lower $R e(R e=187$ and 316$)$, the decrease of $S_{\mathrm{r}} / W_{\mathrm{c}}$ leads to obvious decrease of $S_{\mathrm{gen}} / S_{\mathrm{gen}, 0}$, while for higher $\operatorname{Re}(\operatorname{Re}=443$, 582 and 715 ), the $S_{\text {gen }} / S_{\text {gen, } 0}$ firstly decreases and then increases, and the turning point of $S_{\mathrm{r}} / W_{\mathrm{c}}$ is larger for larger Re and MCHS-AFR. With the decrease of $S_{\mathrm{r}} / W_{\mathrm{c}}$ from 50 to 2 , the $S_{\mathrm{gen}} / S_{\mathrm{gen}, 0}$ decreases from 0.971 to $0.745,0.952$ to $0.682,0.939$ to 0.709 then $0.715,0.926$ to 0.761 then 0.821, and 0.915 to 0.902 then 1.014 for MCHS-AFR respectively for $R e=187,316,443$, 582 and 715 ; from 0.979 to $0.758,0.936$ to $0.674,0.978$ to 0.678 then $0.685,0.937$ to 0.699 then 0.762 , and 0.934 to 0.739 then 0.896 for MCHS-OFR respectively for $R e=187,316$, 443, 582 and 715. From Fig. 10b, it can be seen that the increase of $R e$ and decrease of $S_{\mathrm{r}} / W_{\mathrm{c}}$ result in large decrease of $S_{\mathrm{gen,h}} / S_{\mathrm{gen},}$ and the decrease rate of $S_{\mathrm{gen,}, \mathrm{h}} / S_{\mathrm{gen}}$ with $R e$ increases with decrease of $S_{\mathrm{r}} / W_{\mathrm{c}}$. With the decrease of $S_{\mathrm{r}} / W_{\mathrm{c}}$ from 50 to 2 , the $S_{\mathrm{gen,h}} / S_{\mathrm{gen}}$ decreases from 0.999 to $0.995,0.994$ to $0.958,0.981$ to $0.869,0.959$ to 0.72 , and 0.929 to 0.542 for MCHS-AFR respectively for $R e=187,316,443,582$ and 715 ; from 0.999 to $0.996,0.994$ to $0.966,0.981$ 
to $0.891,0.958$ to 0.766 , and 0.925 to 0.634 for MCHS-OFR respectively for $R e=187,316$, 443, 582 and 715.

\subsection{Performance evaluation criterion}

Figure 11 shows the effects of $R e$ and $W_{\mathrm{r}} / S_{\mathrm{r}}$ on $P E C$. The geometry of fan-shaped ribs used in these figures is the same to Fig. 8. From Fig. 11a, it is noted that with increase of Re, the $P E C$ firstly increases and then decreases, and the maximum occurs more early for the MCHS-AFR and larger $W_{\mathrm{r}} / S_{\mathrm{r}}$. It can be seen that with the increase of $R e$ and $W_{\mathrm{r}} / S_{\mathrm{r}}$, the $P E C$ can be lower than 1 , indicating that the performance of such heat sink is worse than the MCHS under those conditions. From Fig. $11 \mathrm{~b}$, it can be seen that the $W_{\mathrm{r}} / S_{\mathrm{r}}$ has more influence on PEC for MCHS-OFR than MCHS-AFR, and the MCHS-OFR with $W_{\mathrm{r}} / S_{\mathrm{r}}<0.7$ shows better performance than MCHS-AFR. For MCHS-OFR, as $R e=187$ and 316 , the PEC generally decrease with increase of $W_{\mathrm{r}} / S_{\mathrm{r}}$; as $R e=443,582$ and 715 , the $P E C$ increases as $W_{\mathrm{r}} / S_{\mathrm{r}}<0.3$ and decreases as $W_{\mathrm{r}} / S_{\mathrm{r}}>0.3$. For MCHS-AFR, there is no clear tendency of $P E C$ with $W_{\mathrm{r}} / S_{\mathrm{r}}$. With the increase of $W_{\mathrm{r}} / S_{\mathrm{r}}$ from 0.125 to 1 , the $P E C$ for MCHS-AFR changes in the ranges of $1.01-1.12,1.04-1.16,1.01-1.15,0.96-1.13$ and $0.94-1.09$ respectively for $R e=$ 187, 316, 443, 582 and 715, and the PEC for MCHS-OFR decreases from 1.23 to $1.05,1.37$ to $1.05,1.35$ to 1.37 then $1.03,1.28$ to 1.33 then $0.99,1.21$ to 1.30 then 0.97 .

Figure 12 shows the effects of $R e$ and $H_{\mathrm{r}} / W_{\mathrm{c}}$ on $P E C$. The geometry of fan-shaped ribs used in these figures is the same to Fig. 9. From Fig. 12a, it can be seen that as $H_{\mathrm{r}} / W_{\mathrm{c}}=0.05$, the MCHS-AFR shows larger PEC than MCHS-OFR, while as $H_{\mathrm{r}} / W_{\mathrm{c}}=0.15$ and 0.25 , the $P E C$ shows the contrary tendency, further as $H_{\mathrm{r}} / W_{\mathrm{c}}=0.15$, the $P E C$ extremely increases with 
$R e$. From Fig. 12b, it can be seen that for MCHS-AFR, as $R e=187$ and 316, the $P E C$ firstly decreases, then increases and decreases again with the increase of $H_{\mathrm{r}} / W_{\mathrm{c}}$, while as $R e=443$, 582 and 715 , the $P E C$ firstly increases and then decreases and the maximum occurs more early for larger Re. For MCHS-OFR, the PEC generally increases with $H_{\mathrm{r}} / W_{\mathrm{c}}$, except the cases as $R e=715$ and $H_{\mathrm{r}} / W_{\mathrm{c}}>0.15$. In general, the MCHS-AFR shows better performance than MCHS-AFR as $H_{\mathrm{r}} / W_{\mathrm{c}}<0.15$, while the contrary tendency as $H_{\mathrm{r}} / W_{\mathrm{c}}>0.15$. With the increase of $H_{\mathrm{r}} / W_{\mathrm{c}}$ from 0.05 to 0.25 , the $P E C$ increases from 1.08 to 1.17 then $1.13,1.09$ to 1.26 then $1.11,1.08$ to 1.29 then 1.11 , and 1.08 to 1.33 then 1.08 , for MCHS-AFR respectively at $R e=316,443,582$ and 715 ; from 1.04 to $1.19,1.06$ to $1.29,1.05$ to $1.32,1.04$ to $1.33,1.03$ to 1.29 for MCHS-OFR respectively at $R e=187,316,443,582$ and 715 .

Figure 13 shows the effects of $R e$ and $S_{\mathrm{r}} / W_{\mathrm{c}}$ on $P E C$. The geometry of fan-shaped ribs used in these figures is the same to Fig. 10. From Fig. 13a, it can be seen that as $S_{\mathrm{r}} / W_{\mathrm{c}}=20$ and 10 , the $P E C$ increases with $R e$; as $S_{\mathrm{r}} / W_{\mathrm{c}}=5$ and 2.5 , the $P E C$ firstly increases and then decreases with increase of $R e$. From Fig. $13 \mathrm{~b}$, it is noted that with decrease of $S_{\mathrm{r}} / W_{\mathrm{c}}$, the $P E C$ firstly increases and then decrease for both MCHS-AFR and MCHS-OFR; The maximums of PEC for MCHS-AFR usually occur at a larger $S_{\mathrm{r}} / W_{\mathrm{c}}$ in the range of from 4 to 12.5 ; The maximums of PEC for MCHS-OFR are much higher than MCHS-AFR. With the decrease of $S_{\mathrm{r}} / W_{\mathrm{c}}$ from 50 to 2 , the $P E C$ changes in the range of $0.99-1.07,1.02-1.14,1.03-1.14$, 0.99-1.17, and 0.95-1.16 for MCHS-AFR respectively for $R e=187,316,443,582$ and 715; $0.97-1.23,0.99-1.34,0.99-1.32,1.01-1.32$ and 1.02-1.33 for MCHS-OFR respectively for $R e$ $=187,316,443,582$ and 715. From Figs. 11, 12 and 13, it also can be found that the $P E C$ is an applicable and flexible design parameter to present the comprehensive thermal 
performance for enhanced heat transfer channels, which simultaneously studies thermal and hydraulic characteristics of heat sink.

\section{Conclusions}

In the third part of the three-part study, the relationship between thermal resistance and pumping power, entropy generation rate and performance evaluation criteria for laminar flow in microchannel heat sinks with fan-shaped ribs on sidewalls have been studied. With respect to the smooth baseline channels, the new conclusions drawn in this paper are summarized as follows:

(1). The geometric parameters of fan-shaped ribs have a significant influence on the performance of such microchannel heat sinks. With the increase of the rib's height, the microchannel heat sinks with offset fan-shaped ribs gradually perform better than the ones with aligned fan-shaped ribs. With the increase of the rib's spacing, the comprehensive performance firstly improved and then gradually deteriorates. The rib's width has more influence on MCHS-OFR than MCHS-AFR. The large rib's width can result in the deterioration of performance.

(2). For the microchannel heat sink with large rib's height and small rib's spacing, the increase of Reynolds number can lead to tremendously increase of entropy generation rate due to fluid friction, which can withdraw the decrease of entropy generation rate due to heat transfer and lead to the increase of total entropy generation rate, making the comprehensive performance worse than the smooth one.

(3). The fan-shaped ribs can lead to better comprehensive performance than MCHS. For 
Reynolds number ranging from 187 to 715 and studied geometric parameters, the best microchannel heat sink shows a $32 \%$ decrease in entropy generation rate and 1.33 in performance evaluation criterion, comparing with the MCHS. 


\section{Acknowledgements}

The work was supported by the Engineering and Physical Sciences Research Council (EPSRC) of the UK through research grant (EP/L001233/1) and the National Natural Science Foundation of China (51576005). 


\section{References}

[1] S. Kandlikar, S Garimella, D. Li, S. Colin, M.R. King, Heat transfer and fluid flow in minichannels and microchannels, Elsevier, 2005.

[2] J.L. Xu, Y.H. Gan, D.C. Zhang, Microscale heat transfer enhancement using thermal boundary layer redeveloping concept, International Journal of Heat and Mass Transfer 48 (2005) 1662-1674.

[3] J.L. Xu, Y.X. Song, W. Zhang, Numerical simulations of interrupted and conventional microchannel heat sinks, International Journal of Heat and Mass Transfer 51 (2008) 5906-5917.

[4] L. Chai, G.D. Xia, L. Wang, Heat transfer enhancement in microchannel heat sinks with periodic expansion-constriction cross-sections, International Journal of Heat and Mass Transfer 62 (2013) 741-751.

[5] L. Chai, G.D. Xia, M.Z. Zhou, Numerical simulation of fluid flow and heat transfer in a microchannel heat sink with offset fan-shaped reentrant cavities in sidewall, International Communications in Heat and Mass Transfer 38 (2011) 577-584.

[6] Y.J. Cheng, Numerical simulation of stacked microchannel heat sink with mixing-enhanced passive structure, International Communications in Heat and Mass Transfer 34 (2007) 295-303.

[7] F. Hong, P. Cheng, Three dimensional numerical analyses and optimization of offset strip-fin microchannel heat sinks, International Communications in Heat and Mass 
Transfer 36 (2009) 651-656.

[8] A.J. Foong, N. Ramesh, Laminar convective heat transfer in a microchannel with internal longitudinal fins, International Journal of Thermal Sciences 48 (2009) 1908-1913.

[9] L. Chai, G. Xia, M. Zhou, J. Li, J. Qi, Optimum thermal design of interrupted microchannel heat sink with rectangular ribs in the transverse microchambers, Applied Thermal Engineering 51 (2013) 880-889.

[10] S. Kandlikar, S Garimella, D. Li, S. Colin, M.R. King, Heat transfer and fluid flow in minichannels and microchannels, Elsevier, 2005.

[11] T.H. Tsai, R. Chein, Simple model for predicting microchannel heat sink performance and optimization, Heat and Mass Transfer 48 (2012) 789-798.

[12] D. Liu, S.V. Garimella, Analysis and optimization of the thermal performance of microchannel heat sinks, International Journal of Numerical Methods for Heat \& Fluid Flow 15 (2005) 7-26.

[13] S. Vishal, D. Liu, S.V. Garimella, Analysis of pumping requirements for microchannel cooling systems, ASME 2003 International Electronic Packaging Technical Conference and Exhibition. American Society of Mechanical Engineers, 2003.

[14] S.V. Garimella, S. Vishal, Single-phase flow and heat transport and pumping considerations in microchannel heat sinks, Heat transfer engineering 25 (2004) 15-25.

[15] L. Gosselin, A. Bejan, Tree networks for minimal pumping power, International Journal of Thermal Sciences 44 (2005) 53-63. 
[16] P. Canhoto, A.H. Reis, Optimization of forced convection heat sinks with pumping power requirements, International Journal of Heat and Mass Transfer 54 (2011) 1441-1447.

[17] G. Xie, H. Shen, C.C. Wang, Parametric study on thermal performance of microchannel heat sinks with internal vertical Y-shaped bifurcations, International Journal of Heat and Mass Transfer 90 (2015) 948-958.

[18] M. Famouri, K. Hooman, F. Hooman, Effects of thermal boundary condition, fin size, spacing, tip clearance, and material on pressure drop, heat transfer, and entropy generation optimization for forced convection from a variable-height shrouded fin array, Heat Transfer Research 40 (2009).

[19] Z. Shi, T. Dong, Entropy generation and optimization of laminar convective heat transfer and fluid flow in a microchannel with staggered arrays of pin fin structure with tip clearance, Energy Conversion and Management 94 (2015) 493-504.

[20] P. Promvonge, S. Sripattanapipat, S. Kwankaomeng, Laminar periodic flow and heat transfer in square channel with $45^{\circ}$ inline baffles on two opposite walls, International Journal of Thermal Sciences 49 (2010) 963-975.

[21] G.D. Xia, L. Chai, M.Z. Zhou, Effects of structural parameters on fluid flow and heat transfer in a microchannel with aligned fan-shaped reentrant cavities, International Journal of Thermal Sciences 50 (2011) 411-419.

[22] G.D. Xia, L. Chai, H.Y. Wang, Optimum thermal design of microchannel heat sink with triangular reentrant cavities, Applied Thermal Engineering 31 (2011) 1208-1219.

[23] J. Zhang, Y. Zhao, Y. Diao, Y. Zhang, An experimental study on fluid flow and heat 
transfer in a multiport minichannel flat tube with micro-fin structures, International Journal of Heat and Mass Transfer 84 (2015) 511-520.

[24] F.P. Incropera, Liquid cooling of electronic devices by single-phase convection, Wiley, 1999.

[25] L. Chai, G.D. Xia, H.S. Wang, Numerical study of laminar flow and heat transfer in microchannel heat sink with offset ribs on sidewalls, Applied Thermal Engineering 92 (2016) 32-41.

[26] P. Loosen, Cooling and packaging of high-power diode lasers, High-Power Diode Lasers, Springer Berlin Heidelberg 78 (2000) 289-301.

[27] W.A. Khan, M.M. Yovanovich, J.R. Culham, Optimization of microchannel heat sinks using entropy generation minimization method. In Semiconductor Thermal Measurement and Management Symposium, 22 ${ }^{\text {nd }}$ IEEE Twenty-Second Annual IEEE, 2006, 78-86.

[28] R.L. Webb, Performance evaluation criteria for use of enhanced heat transfer surfaces in heat exchanger design, International Journal of Heat and Mass Transfer 24 (1981) $715-726$. 


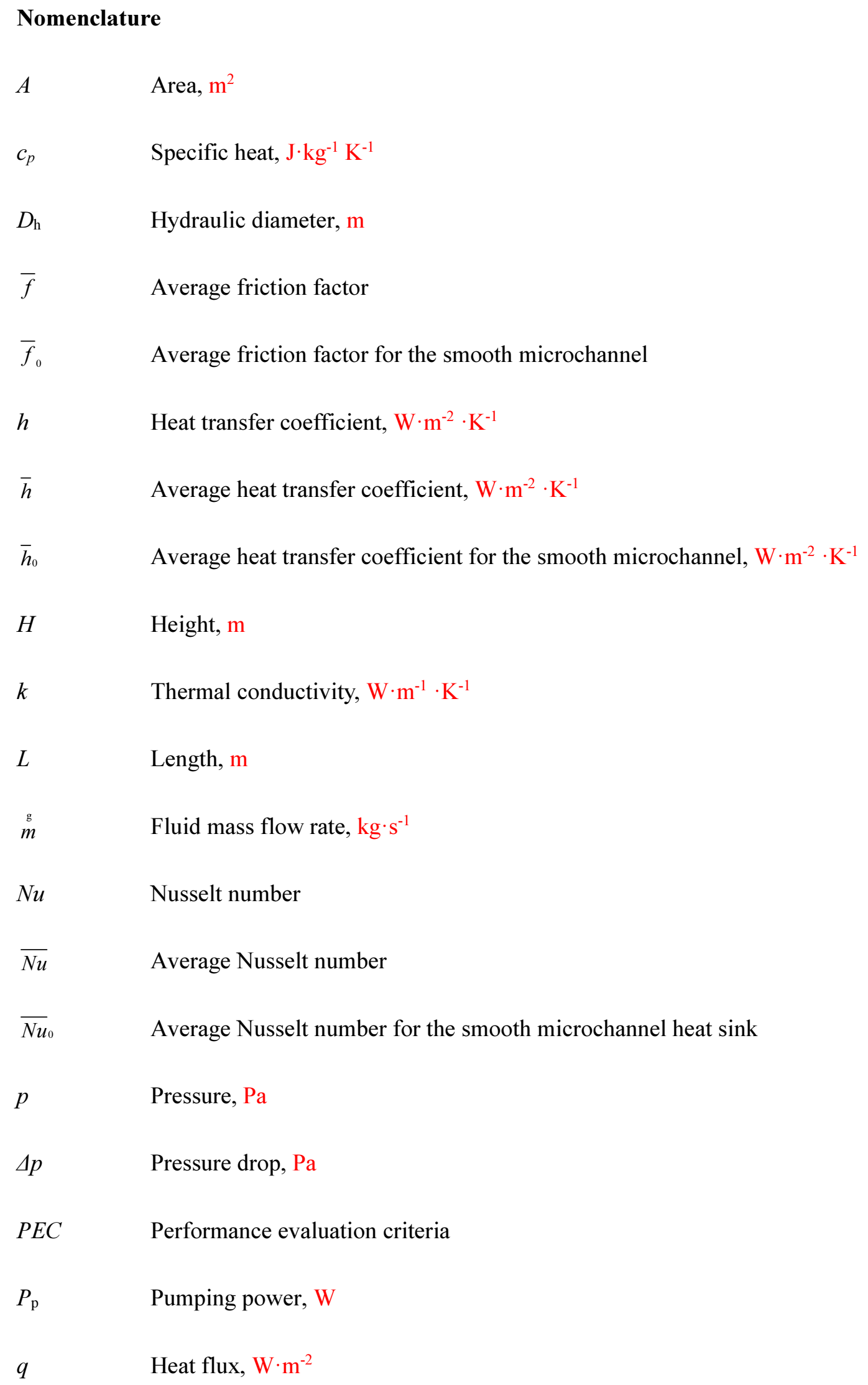




\begin{tabular}{|c|c|}
\hline$Q$ & Heat transfer rate, $\mathrm{W}$ \\
\hline $\operatorname{Re}$ & Reynolds number \\
\hline$R_{\mathrm{th}}$ & Total thermal resistance, $\mathrm{K} \cdot \mathrm{W}^{-1}$ \\
\hline$S_{\text {gen }}$ & Entropy generation rate, $\mathrm{W} \cdot \mathrm{K}^{-1}$ \\
\hline$S_{\text {gen,h }}$ & Entropy generation rate due to heat transfer, $\mathrm{W} \cdot \mathrm{K}^{-1}$ \\
\hline$S_{\text {gen,f }}$ & Entropy generation rate due to fluid friction, $\mathrm{W} \cdot \mathrm{K}^{-1}$ \\
\hline$T$ & Temperature, $\mathrm{K}$ \\
\hline $\bar{T}$ & Average temperature, $\mathrm{K}$ \\
\hline$u$ & Velocity, $\mathrm{m} \cdot \mathrm{s}^{-1}$ \\
\hline $\bar{u}$ & Average velocity, $\mathrm{m} \cdot \mathrm{s}^{-1}$ \\
\hline$\stackrel{g}{V}$ & Volume flow rate, $\mathrm{m}^{3} \cdot \mathrm{s}^{-1}$ \\
\hline$x, y, z$ & Three coordinates shown in Fig. 1, m \\
\hline \multicolumn{2}{|c|}{ Greek letters } \\
\hline$\rho$ & Density, $\mathrm{kg} \cdot \mathrm{m}^{-3}$ \\
\hline$\mu$ & Dynamic viscosity, $\mathrm{Pa} \cdot \mathrm{s}$ \\
\hline \multicolumn{2}{|c|}{ Subscripts } \\
\hline a & Ambient \\
\hline $\mathrm{c}$ & Cross section \\
\hline in & Inlet \\
\hline $\mathrm{f}$ & Fluid \\
\hline out & Outlet \\
\hline $\mathrm{pp}$ & Pumping power \\
\hline
\end{tabular}


$r$

Rib

S

W

Silicon

Heat sink base 


\section{Figure captions}

Fig. 1 Microchannel heat sinks with fan-shaped ribs on sidewalls. (a) Computational domain. (b) Geometric parameters of fan-shaped ribs.

Fig. 2 Eeffect of $W_{\mathrm{r}} / S_{\mathrm{r}}$ on the relationship between $R_{\mathrm{th}}$ and $P_{\mathrm{p}}\left(W_{\mathrm{c}}=0.1 \mathrm{~mm}, H_{\mathrm{r}}=0.025 \mathrm{~mm}\right.$ and $\left.S_{\mathrm{r}}=0.4 \mathrm{~mm}\right)$.

Fig. 3 Eeffect of $H_{\mathrm{r}} / W_{\mathrm{c}}$ on the relationship between $R_{\mathrm{th}}$ and $P_{\mathrm{p}}\left(W_{\mathrm{c}}=0.1 \mathrm{~mm}, S_{\mathrm{r}}=0.4 \mathrm{~mm}\right.$ and $\left.W_{\mathrm{r}}=0.1 \mathrm{~mm}\right)$.

Fig. 4 Eeffect of $S_{\mathrm{r}} / W_{\mathrm{c}}$ on the relationship between $R_{\mathrm{th}}$ and $P_{\mathrm{p}}\left(W_{\mathrm{c}}=0.1 \mathrm{~mm}, W_{\mathrm{r}}=0.1 \mathrm{~mm}\right.$ and $\left.H_{\mathrm{r}}=0.025 \mathrm{~mm}\right)$.

Fig. 5 Effects of $W_{\mathrm{r}} / S_{\mathrm{r}}$ on $S_{\text {gen }}, S_{\text {gen,h }}$ and $S_{\text {gen, }}\left(W_{\mathrm{c}}=0.1 \mathrm{~mm}, H_{\mathrm{r}}=0.025 \mathrm{~mm}\right.$ and $S_{\mathrm{r}}=0.4$ mm). (a) $S_{\text {gen, versus }} R e$, (b) $S_{\text {gen,h, versus }} R e$ and (c) $S_{\text {gen,f, }}$ versus $R e$.

Fig. 6 Effects of $H_{\mathrm{r}} / W_{\mathrm{c}}$ on $S_{\text {gen, }}, S_{\text {gen,h }}$ and $S_{\text {gen, }}\left(W_{\mathrm{c}}=0.1 \mathrm{~mm}, S_{\mathrm{r}}=0.4 \mathrm{~mm}\right.$ and $\left.W_{\mathrm{r}}=0.1 \mathrm{~mm}\right)$. (a) $S_{\text {gen, }}$ versus $R e$, (b) $S_{\text {gen,h, versus }} R e$ and (c) $S_{\text {gen,f, versus }} R e$.

Fig. 7 Effects of $S_{\mathrm{r}} / W_{\mathrm{c}}$ on $S_{\mathrm{gen}}, S_{\mathrm{gen}, \mathrm{h}}$ and $S_{\mathrm{gen}, \mathrm{f}}\left(W_{\mathrm{c}}=0.1 \mathrm{~mm}, W_{\mathrm{r}}=0.1 \mathrm{~mm}\right.$ and $H_{\mathrm{r}}=0.025$

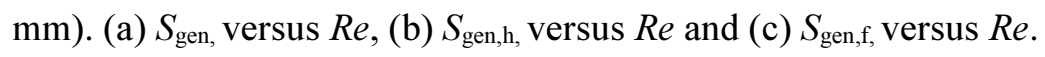

Fig. 8 Effects of $W_{\mathrm{r}} / S_{\mathrm{r}}$ on $S_{\text {gen }} / S_{\text {gen, }, 0}$ and $S_{\text {gen, } \mathrm{h}} / S_{\text {gen }}\left(W_{\mathrm{c}}=0.1 \mathrm{~mm}, H_{\mathrm{r}}=0.025 \mathrm{~mm}\right.$ and $S_{\mathrm{r}}=0.4$

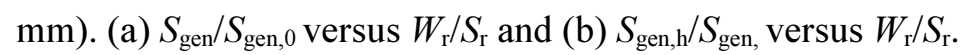

Fig. 9 Effects of $H_{\mathrm{r}} / W_{\mathrm{c}}$ on $S_{\mathrm{gen}} / S_{\mathrm{gen}, 0}$ and $S_{\text {gen,h }} / S_{\text {gen }}\left(W_{\mathrm{c}}=0.1 \mathrm{~mm}, S_{\mathrm{r}}=0.4 \mathrm{~mm}\right.$ and $W_{\mathrm{r}}=0.1$ mm). (a) $S_{\text {gen }} / S_{\text {gen, }, 0}$ versus $H_{\mathrm{r}} / W_{\mathrm{c}}$ and (b) $S_{\text {gen, } \mathrm{l}} / S_{\text {gen, }}$ versus $H_{\mathrm{r}} / W_{\mathrm{c}}$.

Fig. 10 Effects of $S_{\mathrm{r}} / W_{\mathrm{c}}$ on $S_{\text {gen }} / S_{\mathrm{gen}, 0}$ and $S_{\text {gen, } \mathrm{h}} / S_{\text {gen }}\left(W_{\mathrm{c}}=0.1 \mathrm{~mm}, W_{\mathrm{r}}=0.1 \mathrm{~mm}\right.$ and $H_{\mathrm{r}}=$ $0.025 \mathrm{~mm}$ ). (a) $S_{\text {gen }} / S_{\text {gen, }, 0}$ versus $S_{\mathrm{r}} / W_{\mathrm{c}}$ and (b) $S_{\text {gen, } \mathrm{l}} / S_{\text {gen, versus }} S_{\mathrm{r}} / W_{\mathrm{c}}$. 
Fig. 11 Effects of $W_{\mathrm{r}} / S_{\mathrm{r}}$ on $P E C\left(W_{\mathrm{c}}=0.1 \mathrm{~mm}, H_{\mathrm{r}}=0.025 \mathrm{~mm}\right.$ and $\left.S_{\mathrm{r}}=0.4 \mathrm{~mm}\right)$. (a) $P E C$ versus $R e$ and (b) $P E C$ versus $W_{\mathrm{r}} / S_{\mathrm{r}}$.

Fig. 12 Effects of $H_{\mathrm{r}} / W_{\mathrm{c}}$ on $P E C\left(W_{\mathrm{c}}=0.1 \mathrm{~mm}, S_{\mathrm{r}}=0.4 \mathrm{~mm}\right.$ and $\left.W_{\mathrm{r}}=0.1 \mathrm{~mm}\right)$. (a) $P E C$ versus $R e$ and (b) $P E C$ versus $H_{\mathrm{r}} / W_{\mathrm{c}}$.

Fig. 13 Effects of $S_{\mathrm{r}} / W_{\mathrm{c}}$ on $P E C\left(W_{\mathrm{c}}=0.1 \mathrm{~mm}, W_{\mathrm{r}}=0.1 \mathrm{~mm}\right.$ and $\left.H_{\mathrm{r}}=0.025 \mathrm{~mm}\right)$. (a) $P E C$ versus $R e$ and (b) $P E C$ versus $S_{\mathrm{r}} / W_{\mathrm{c}}$. 
Fig.1

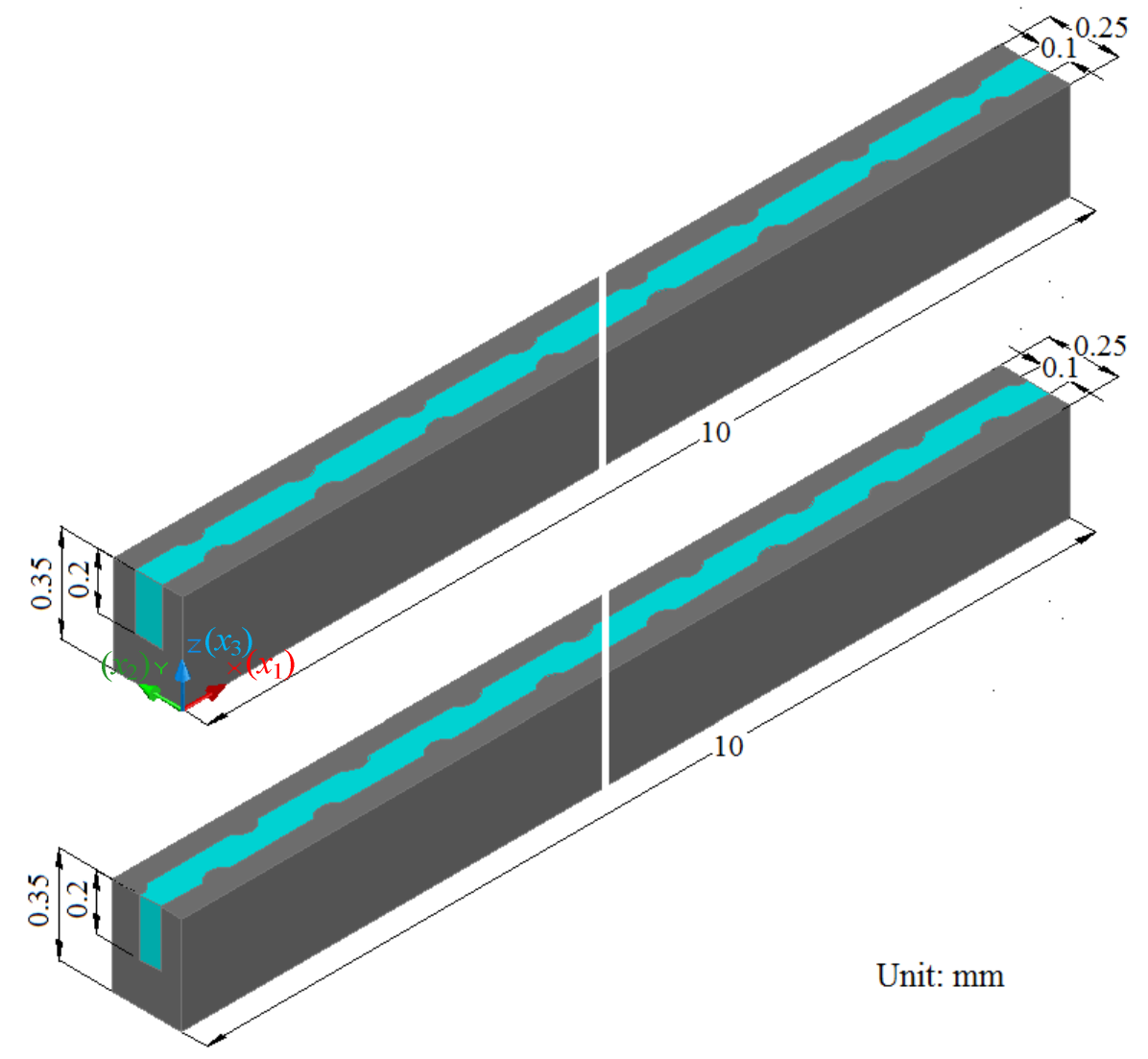

(a)
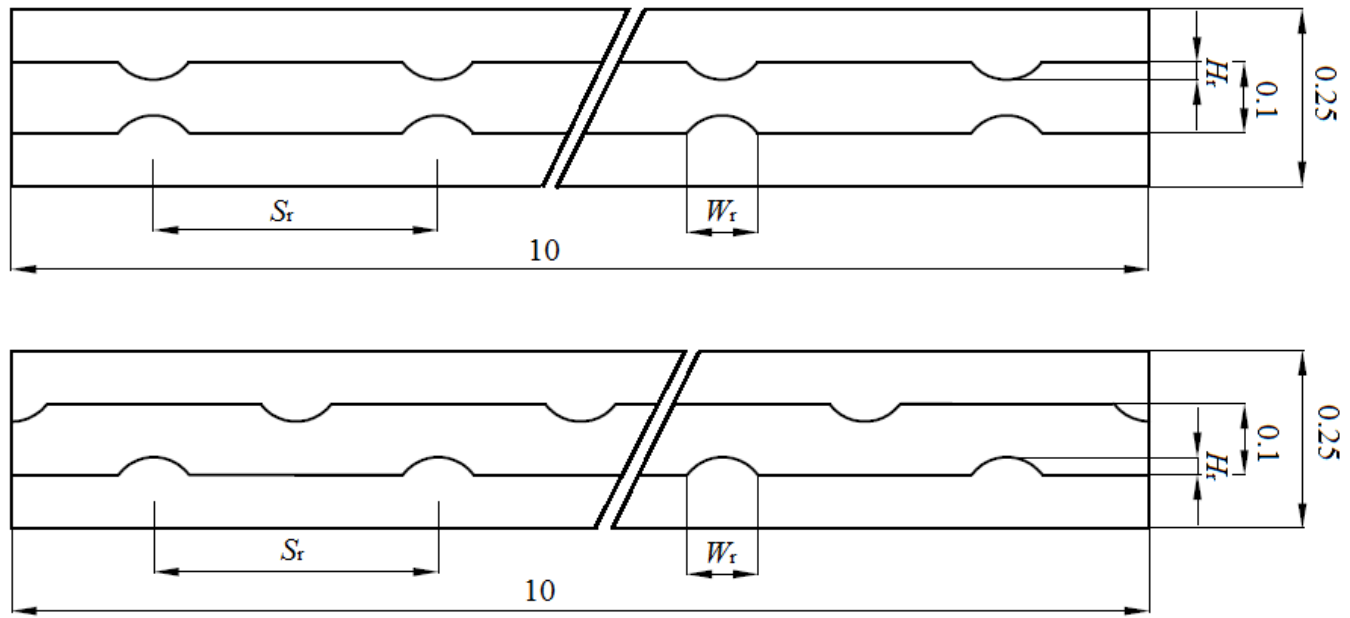

Unit: $\mathrm{mm}$

(b) 
Fig.2

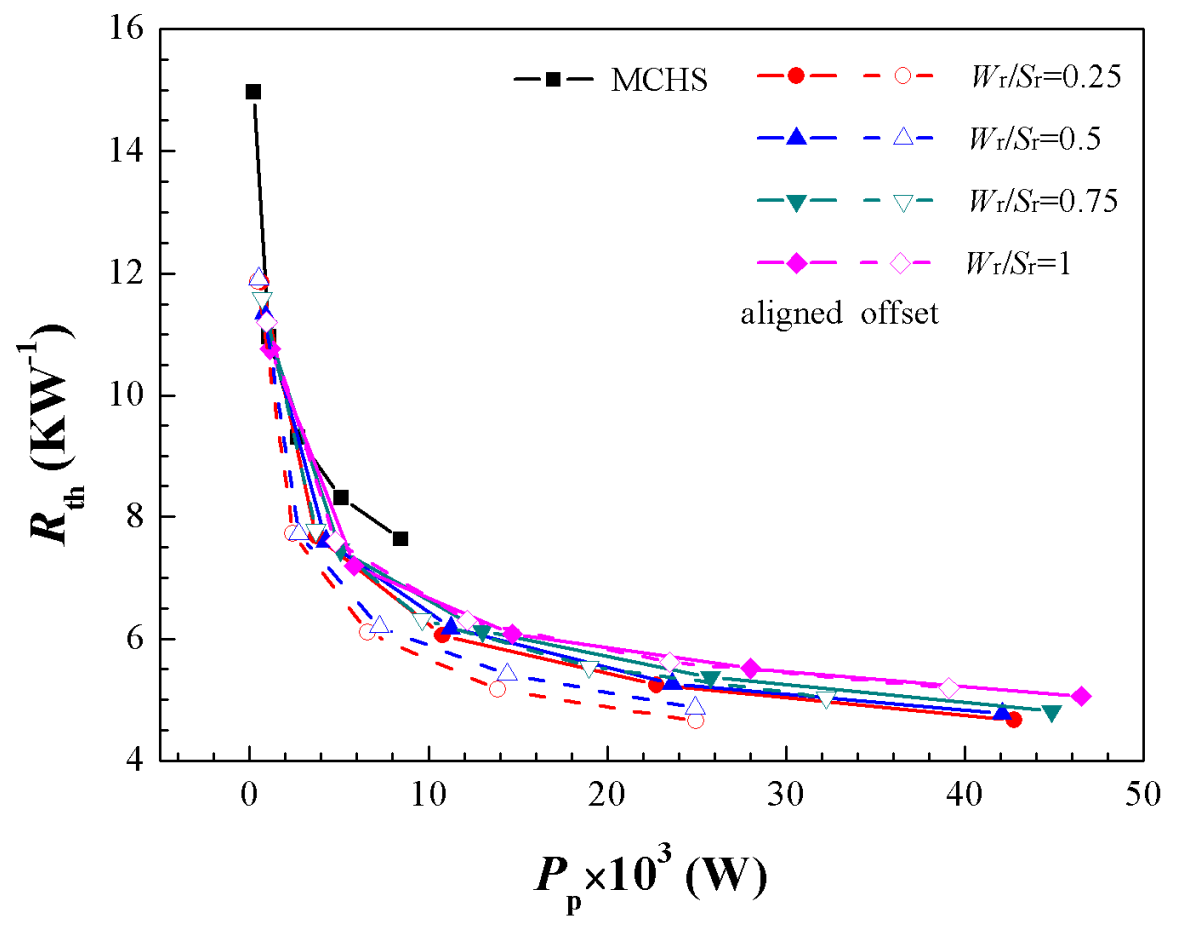


Fig.3

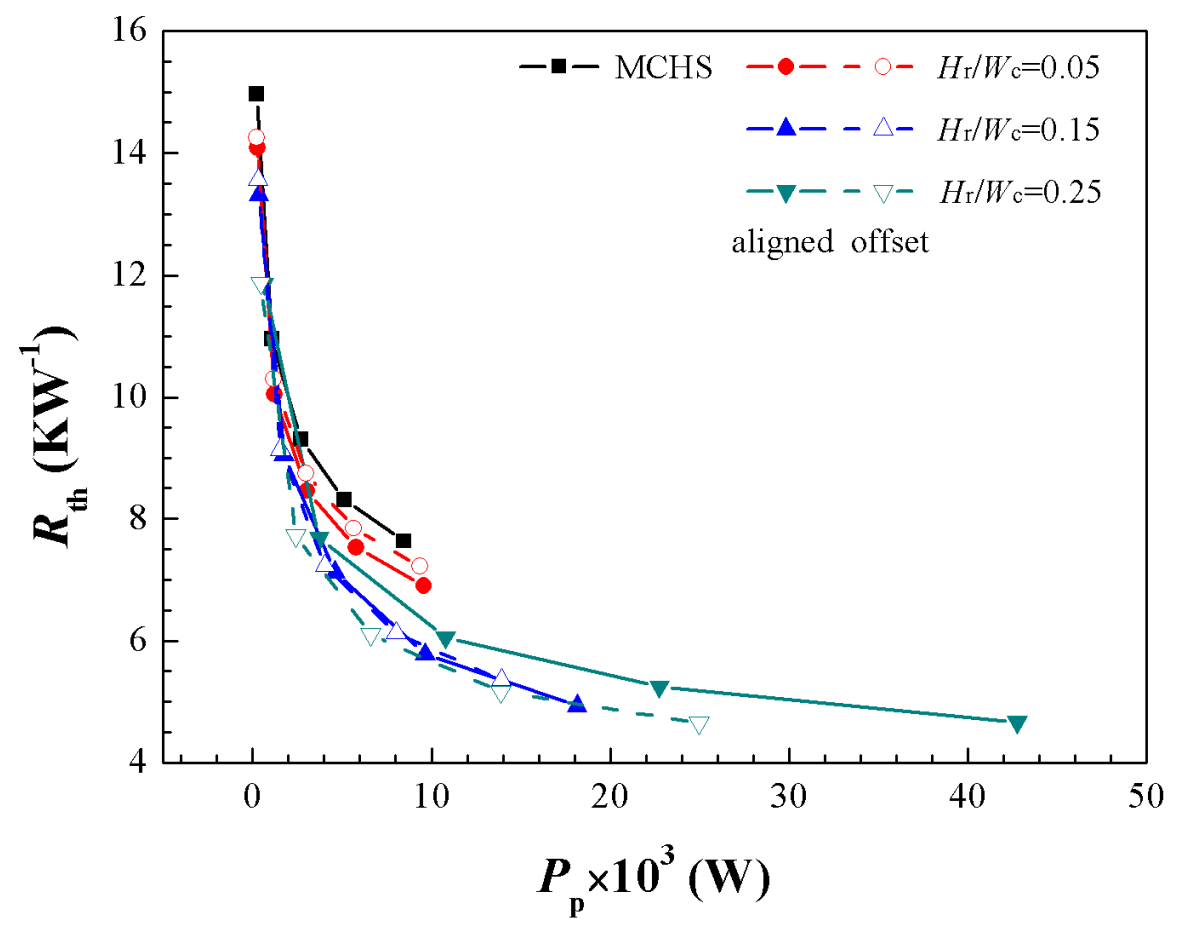


Fig.4

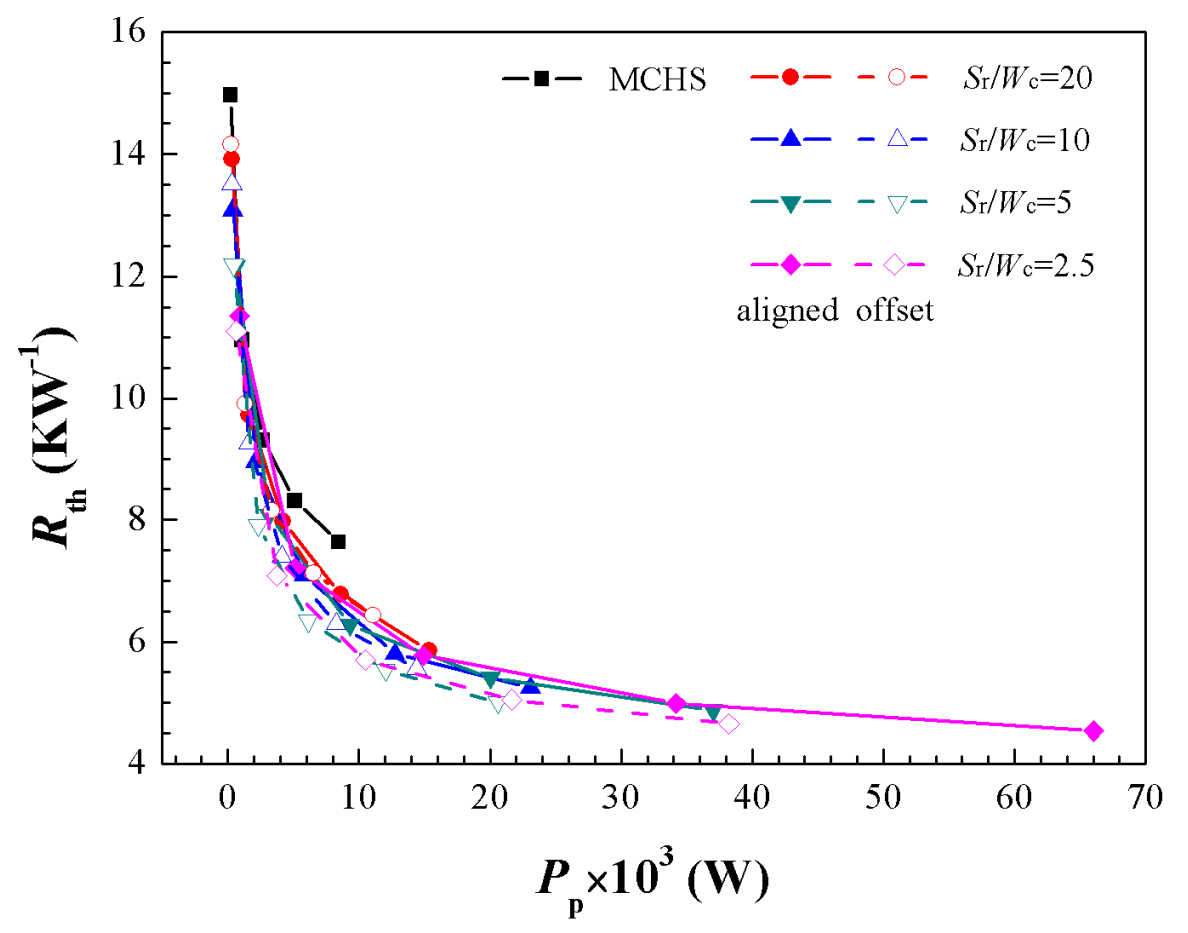


Fig.5

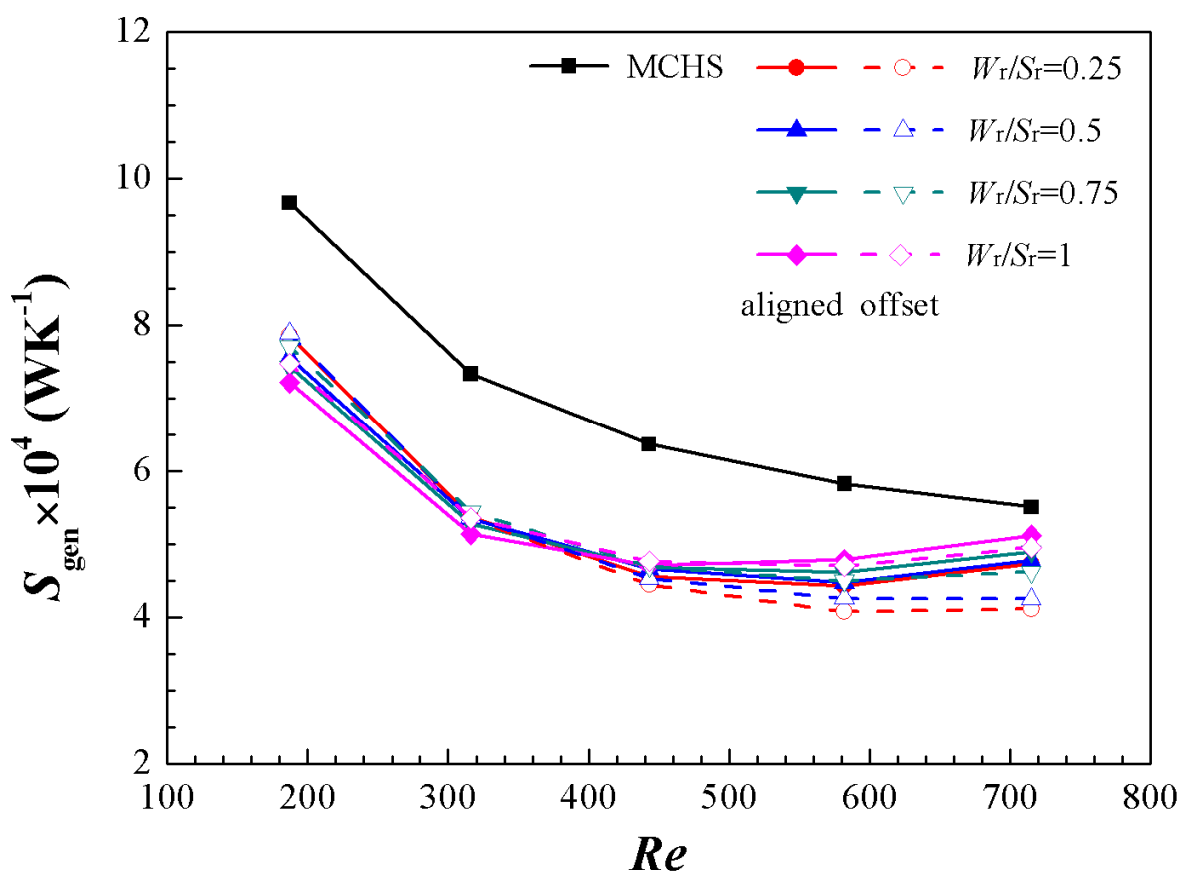

(a)

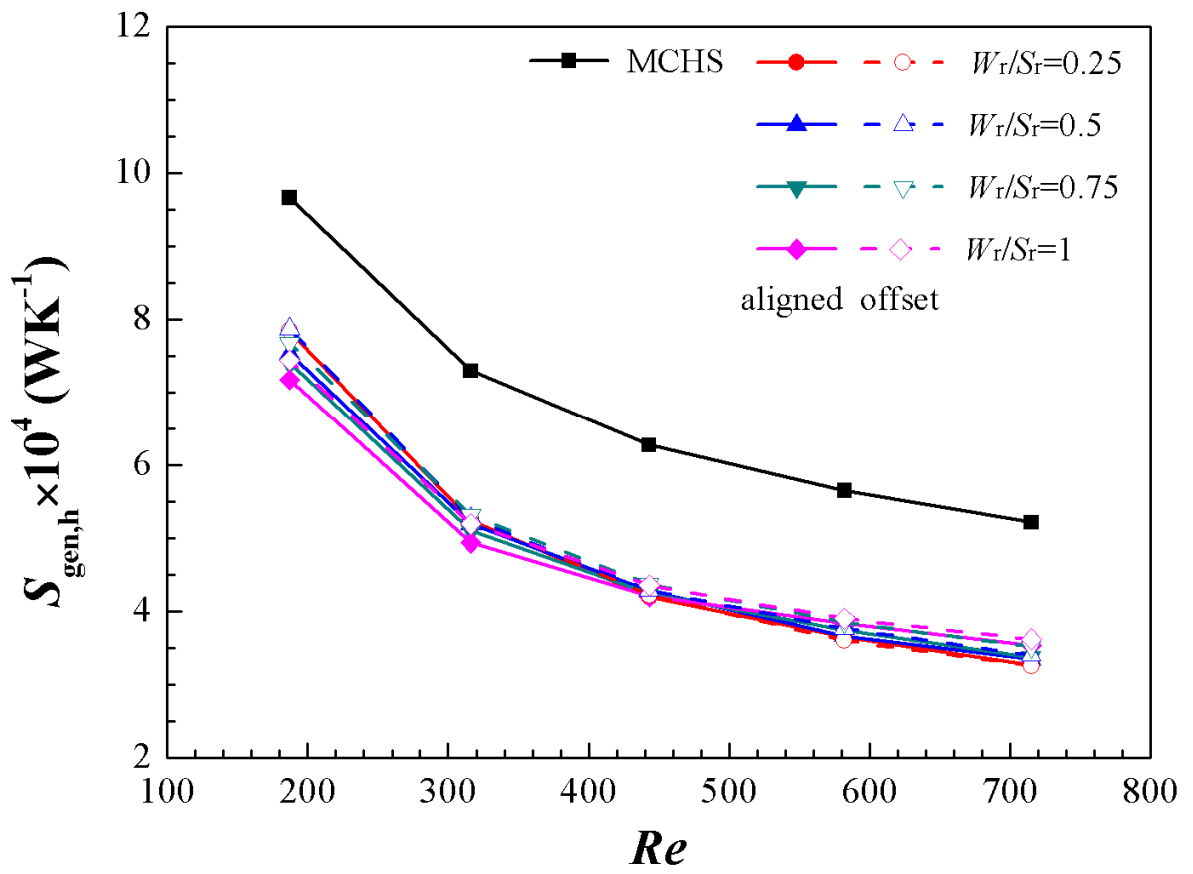

(b) 


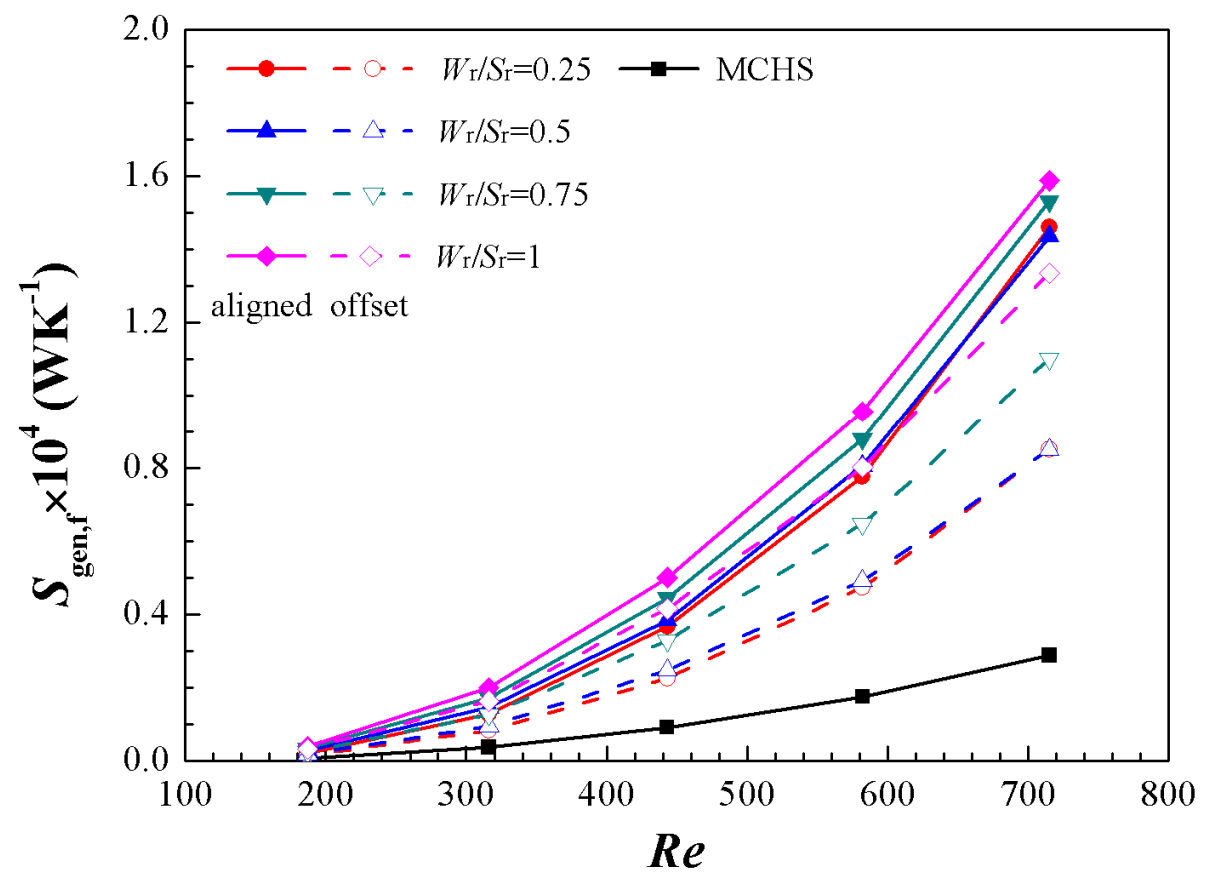

(c) 
Fig.6

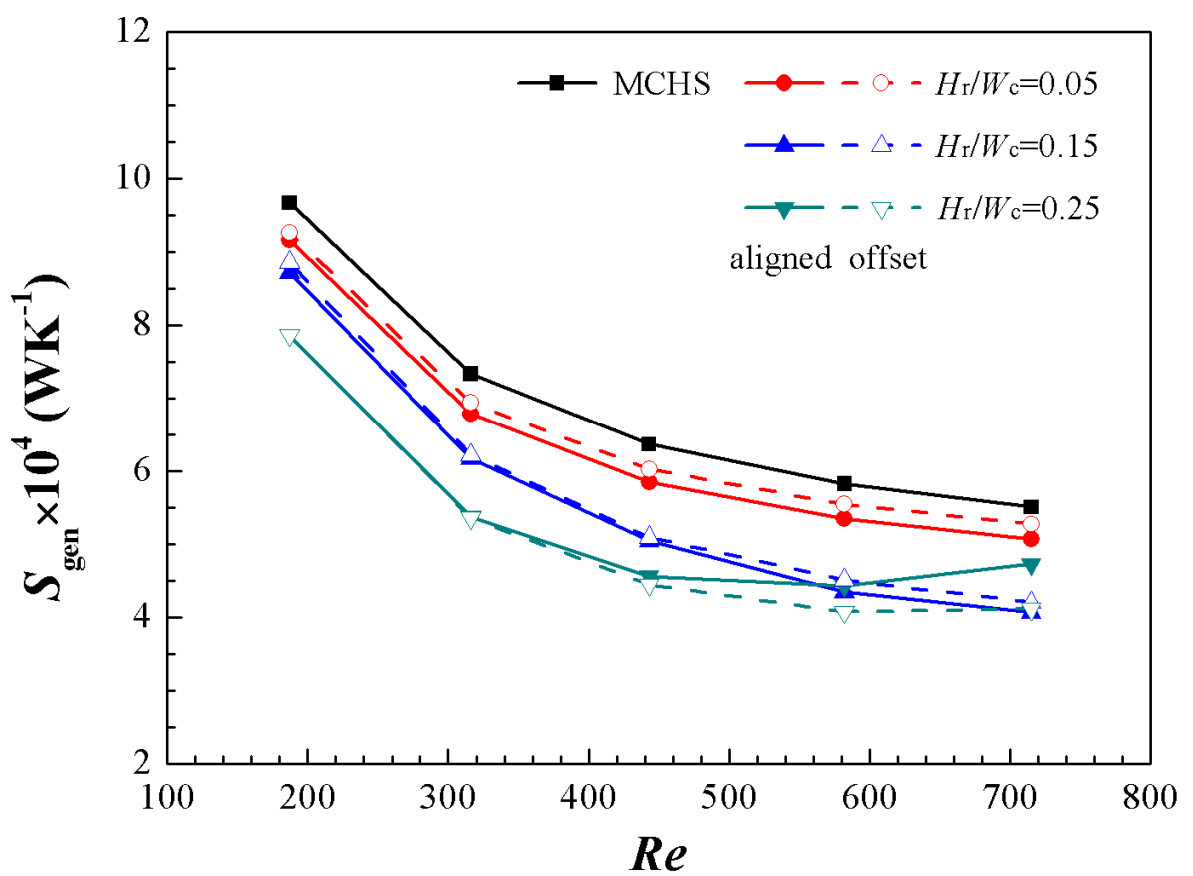

(a)

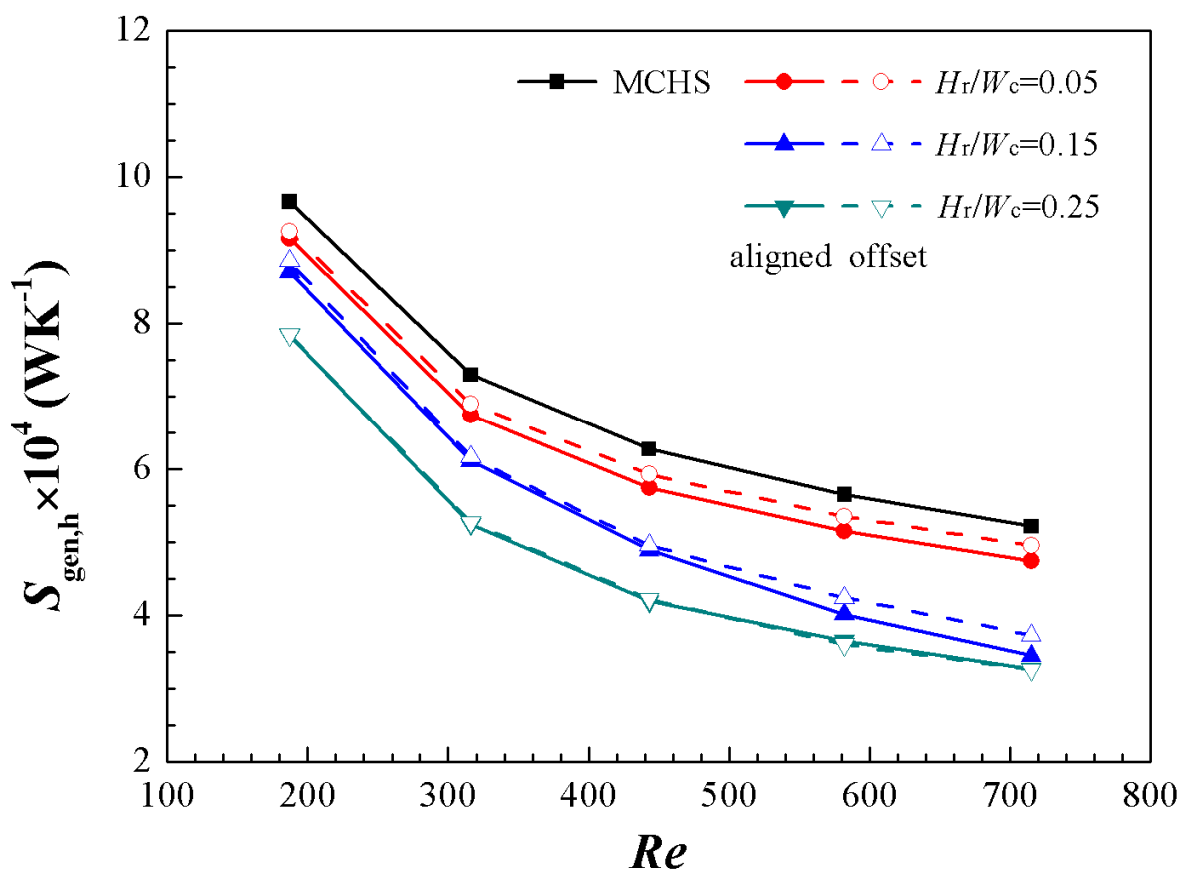

(b) 


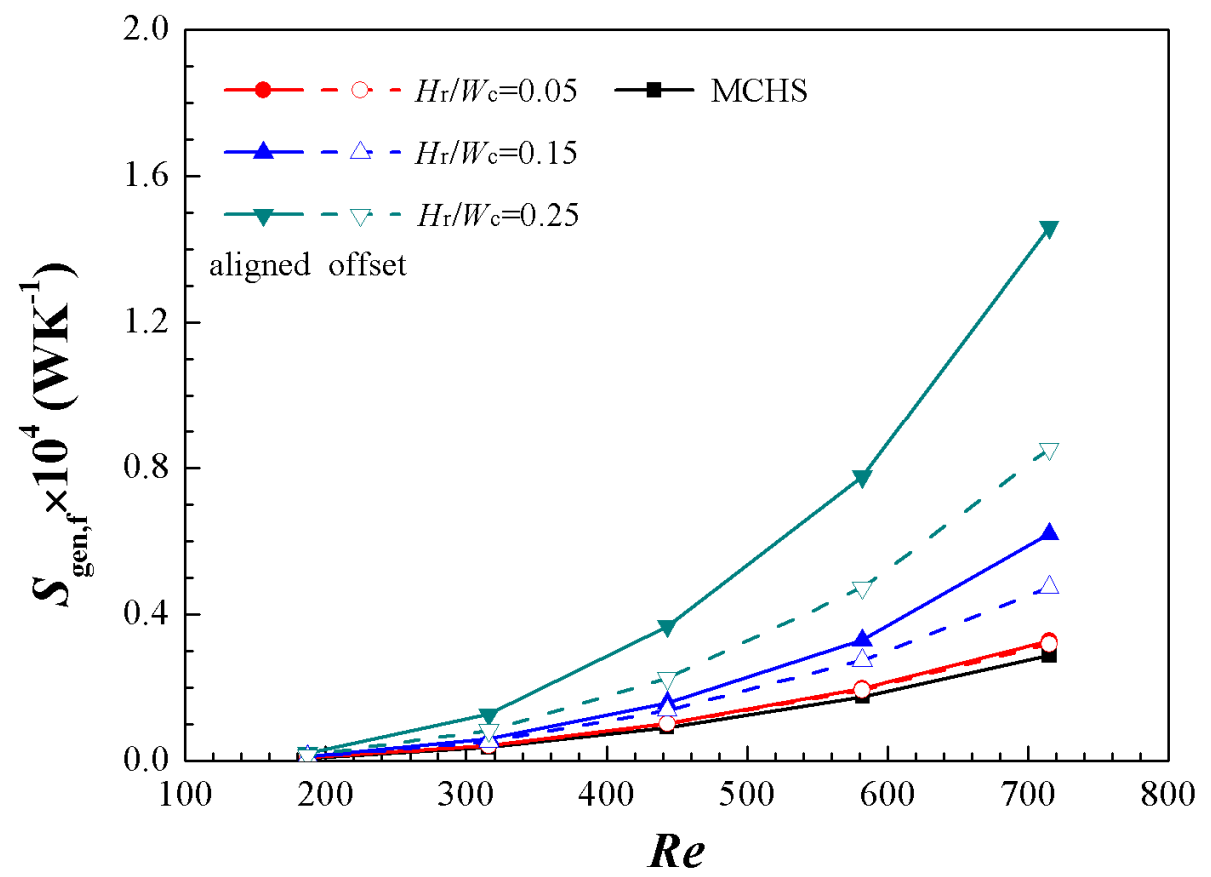

(c) 
Fig.7

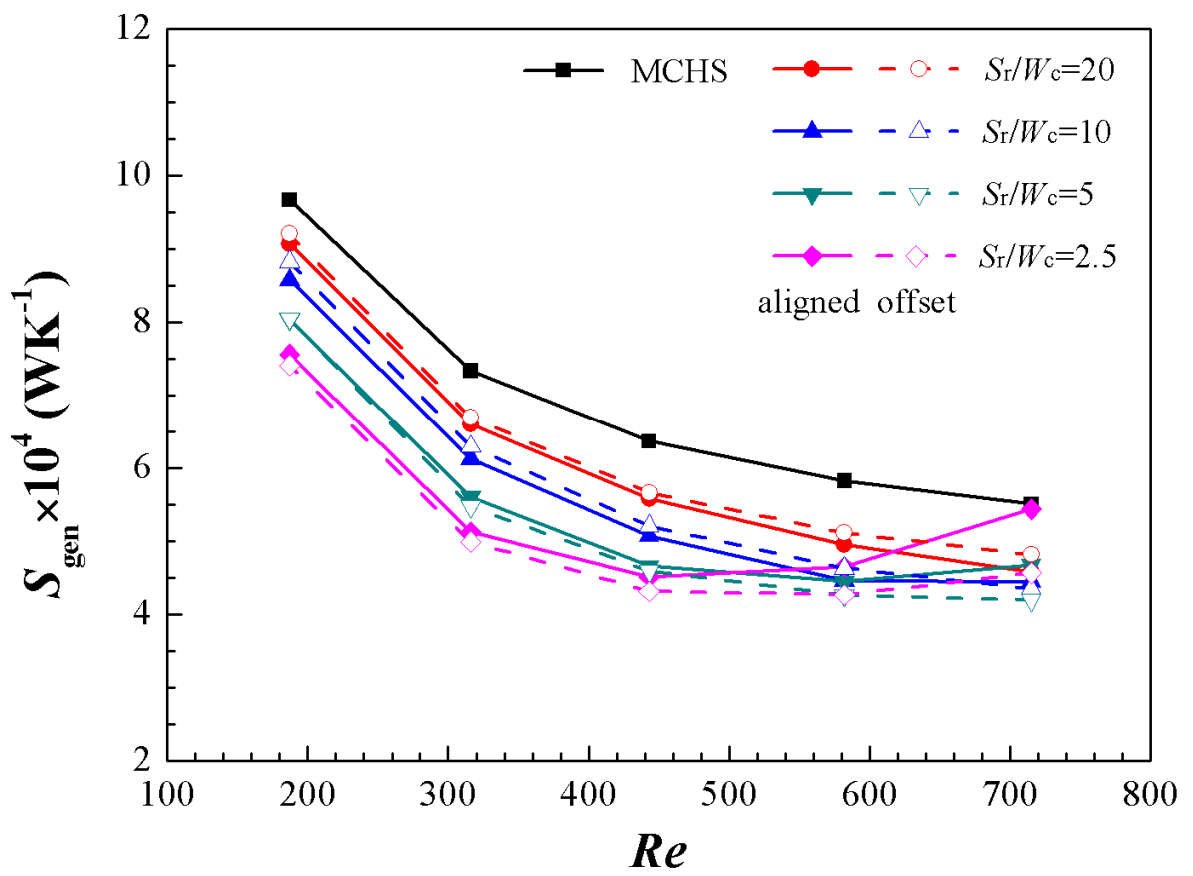

(a)

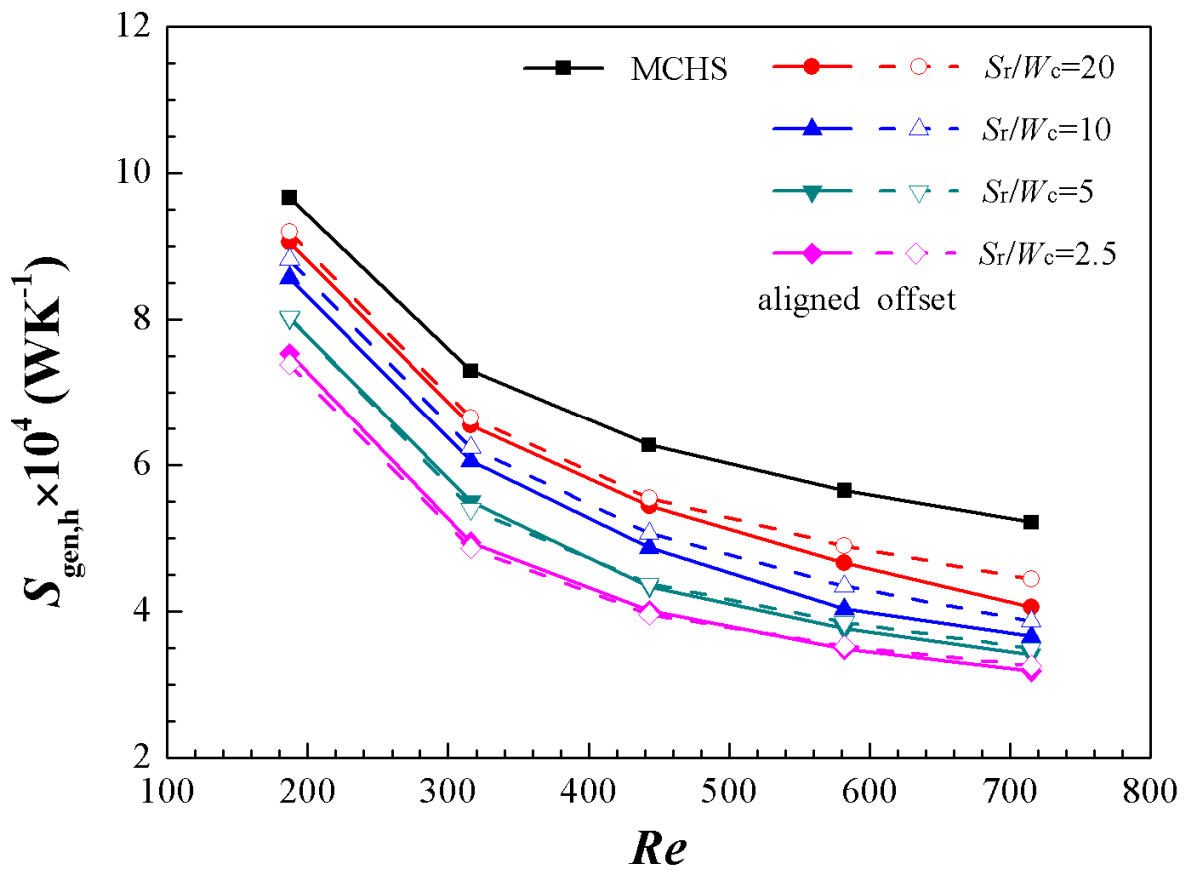

(b) 


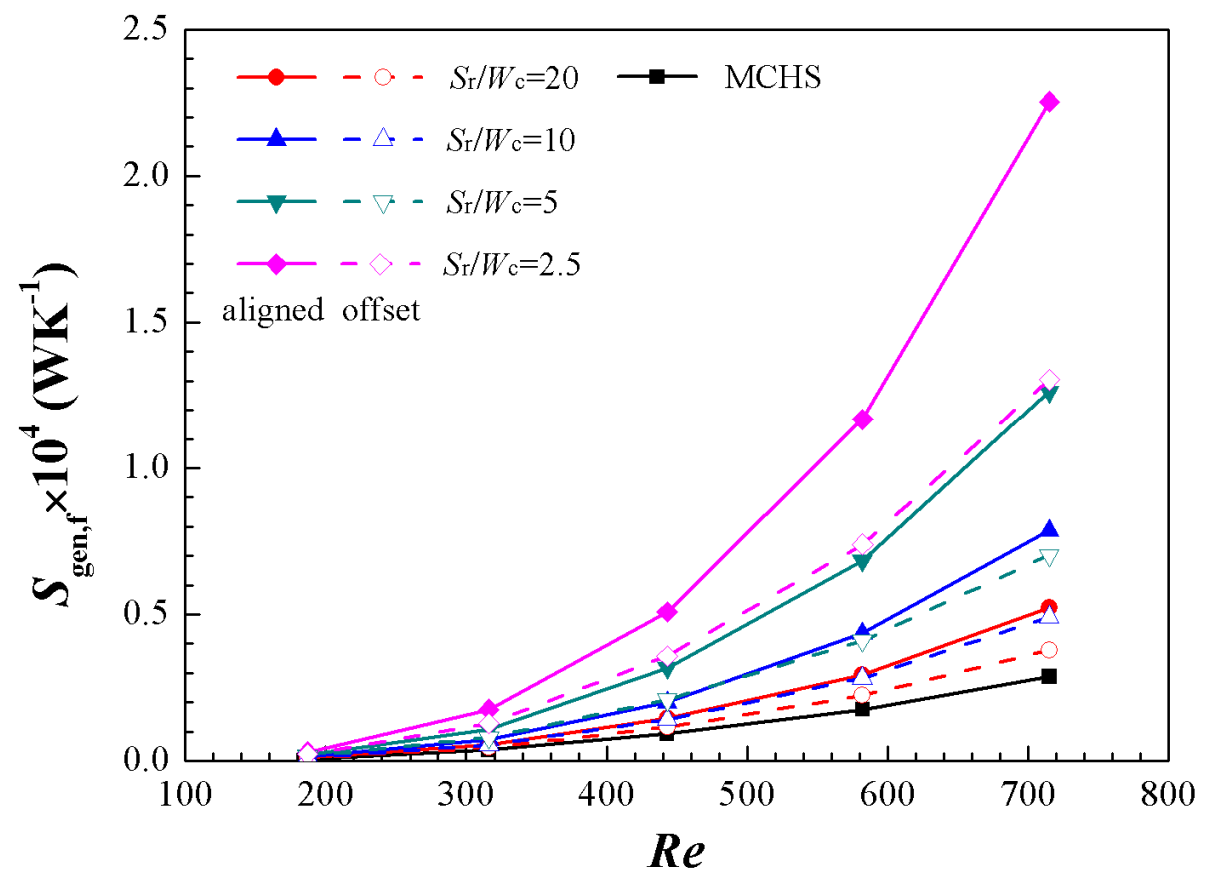

(c) 
Fig. 8

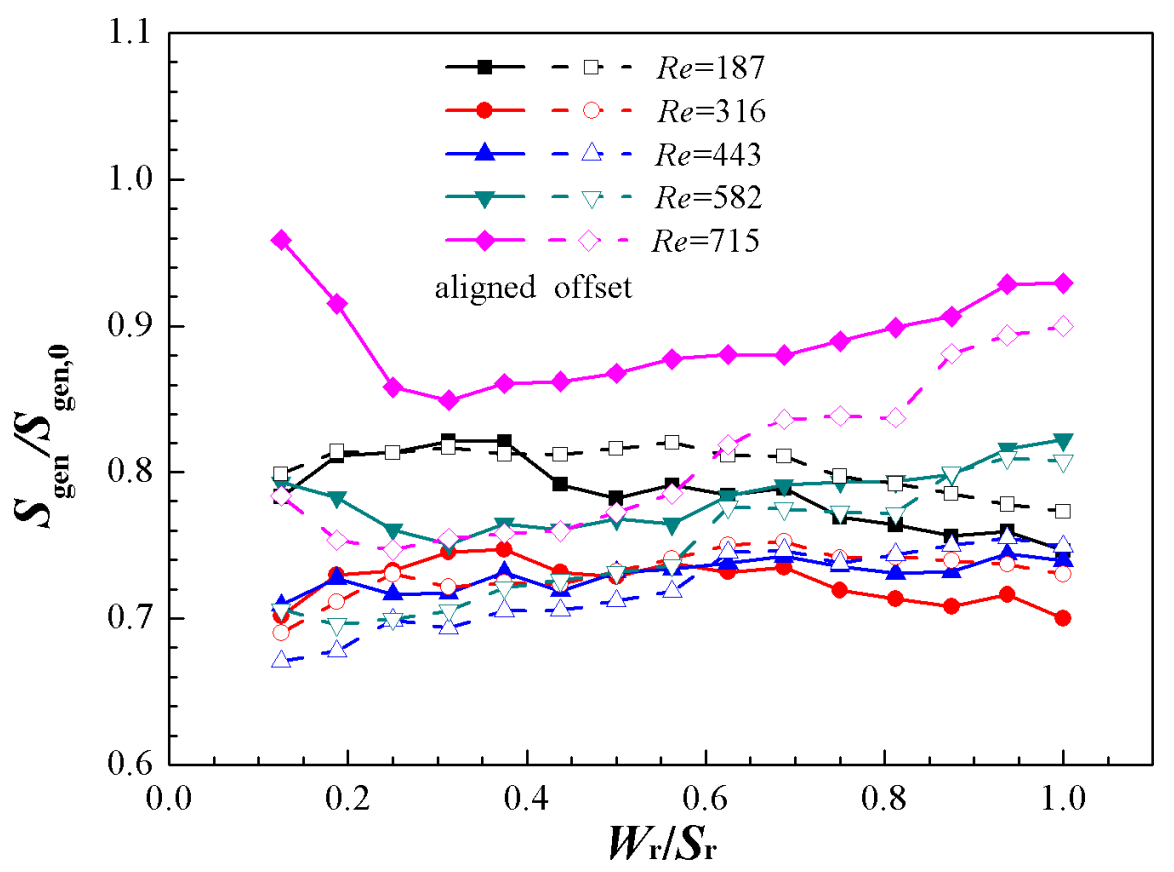

(a)

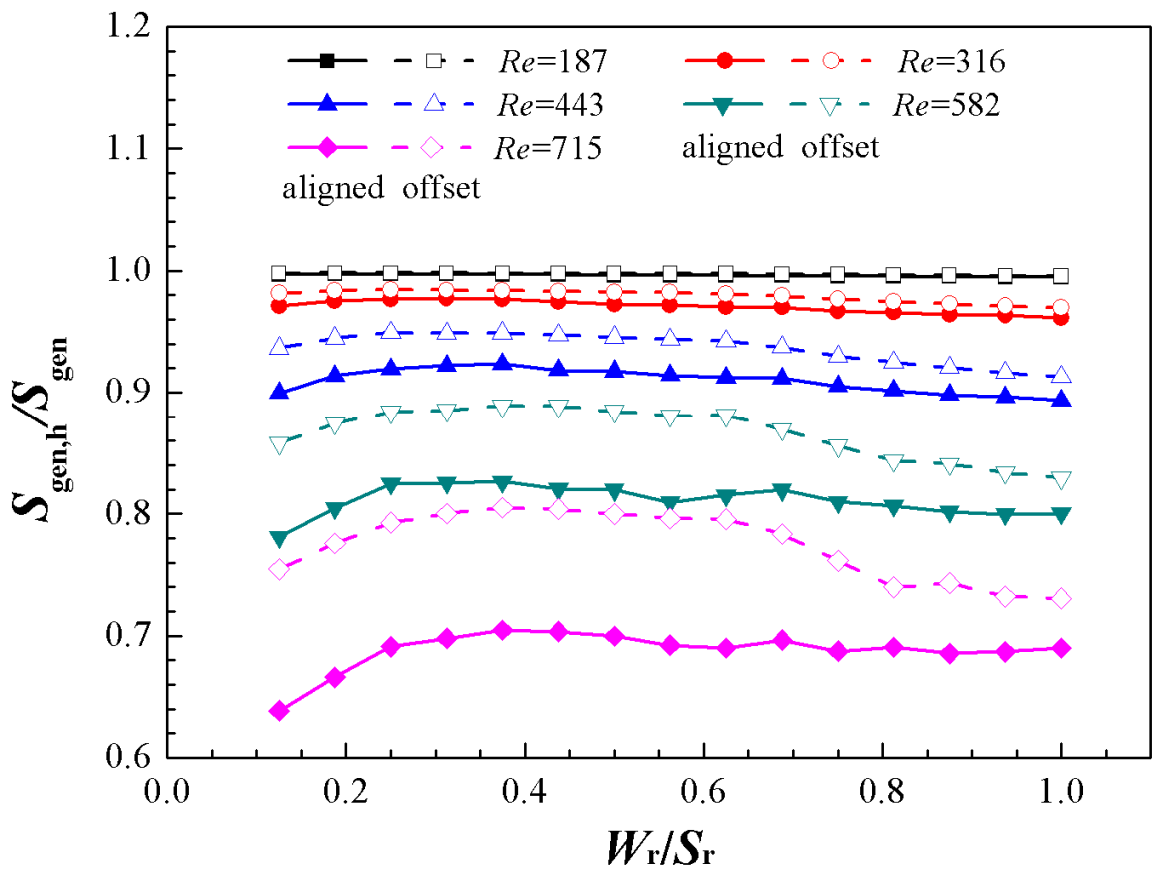

(b) 
Fig.9

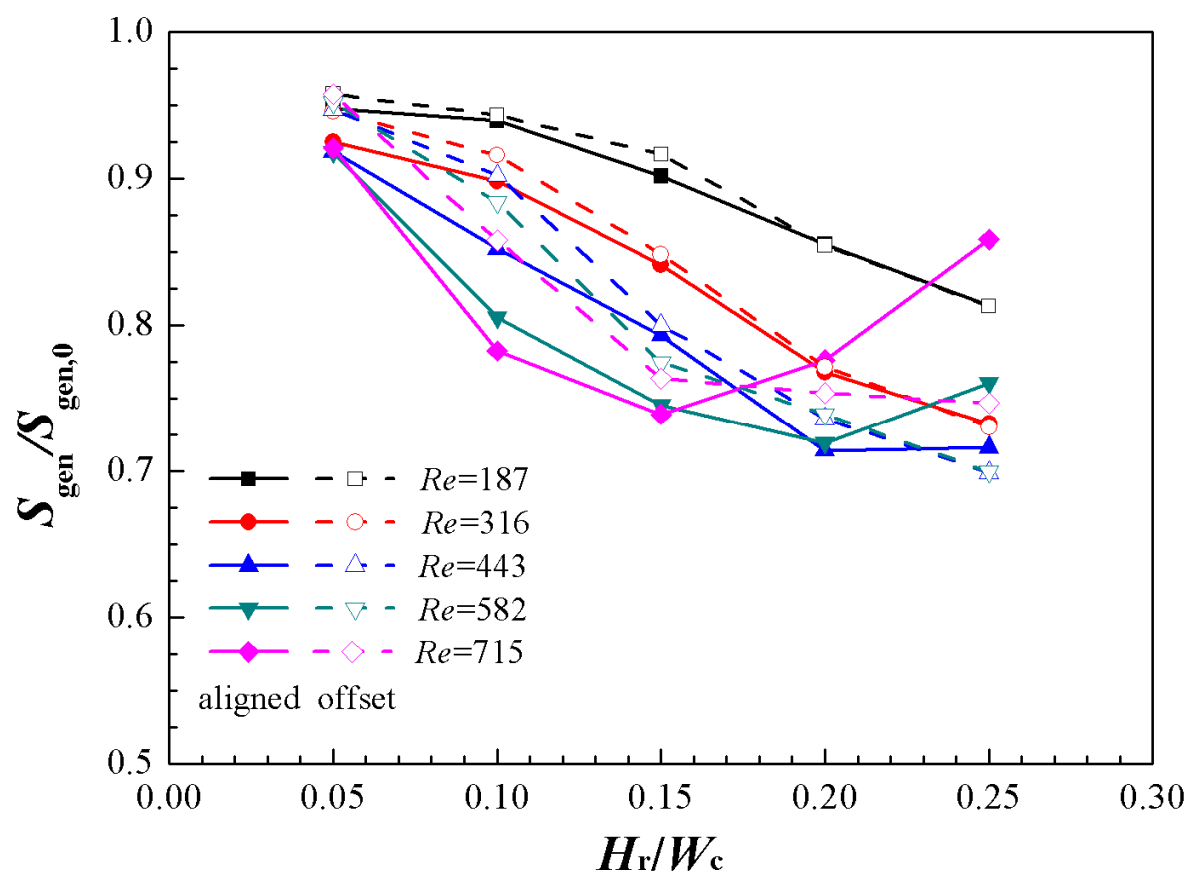

(a)

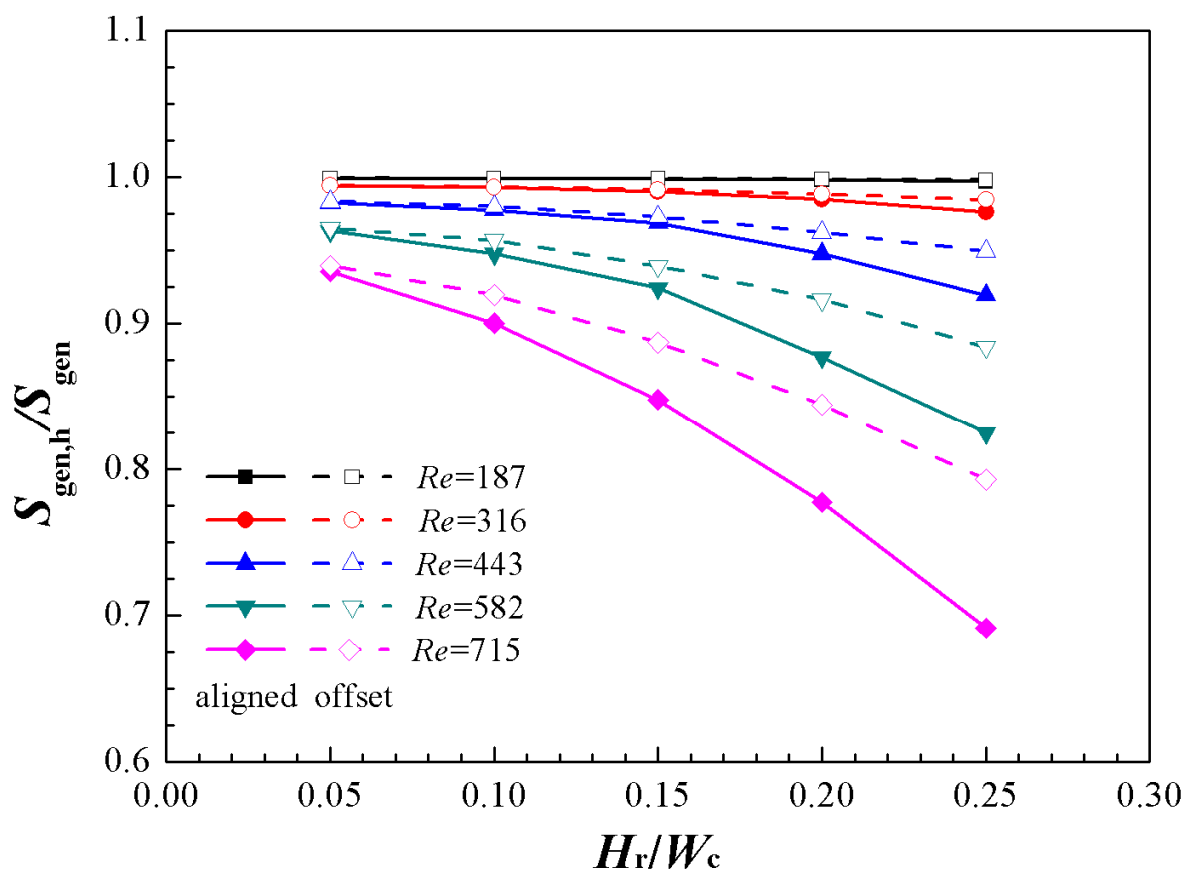

(b) 
Fig. 10

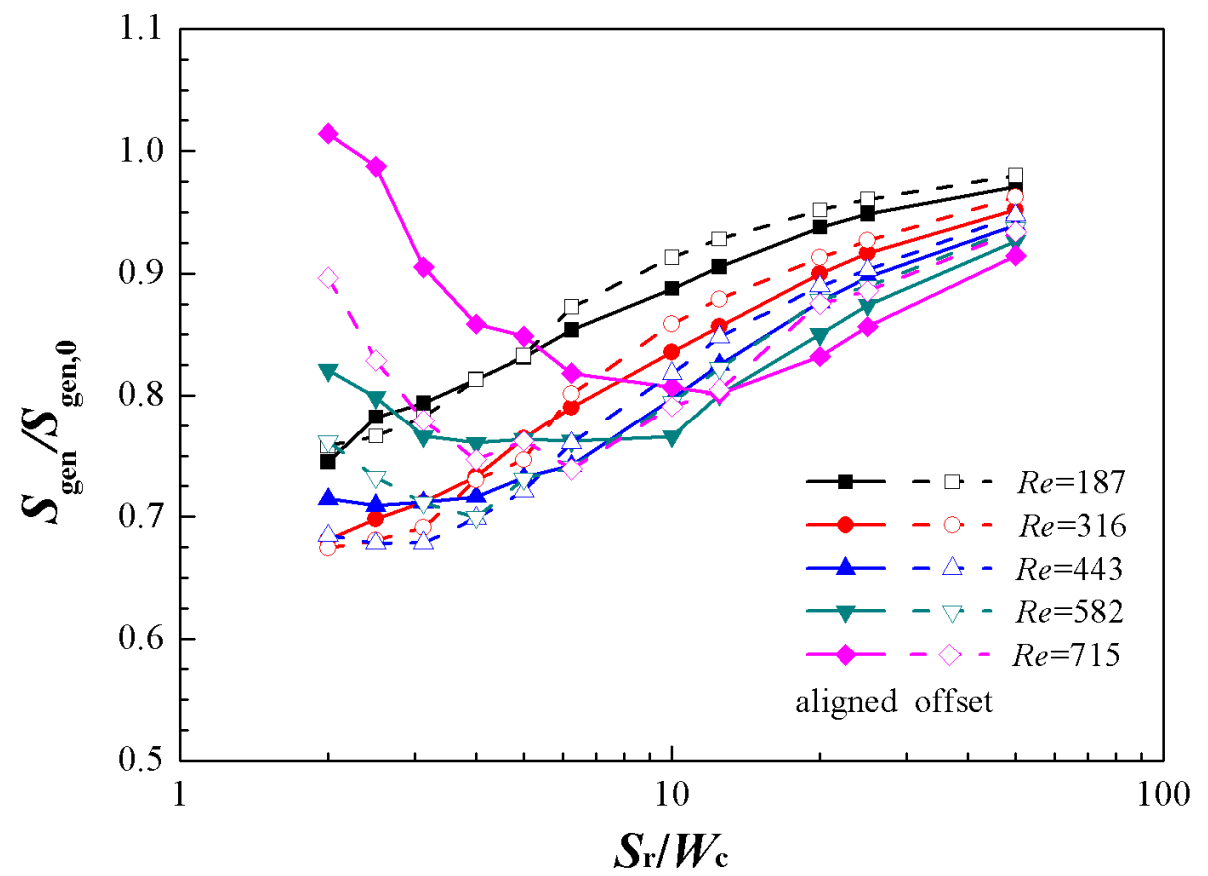

(a)

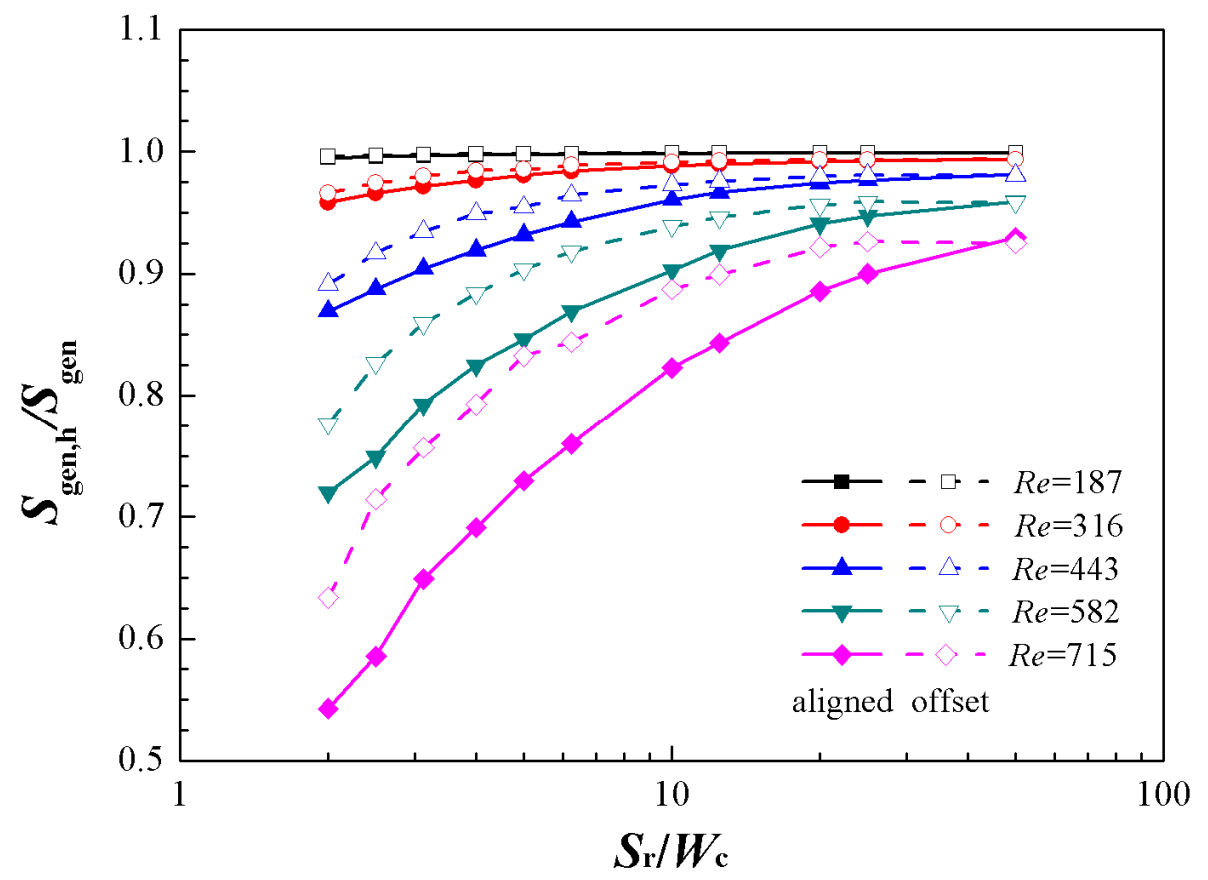

(b) 
Fig.11

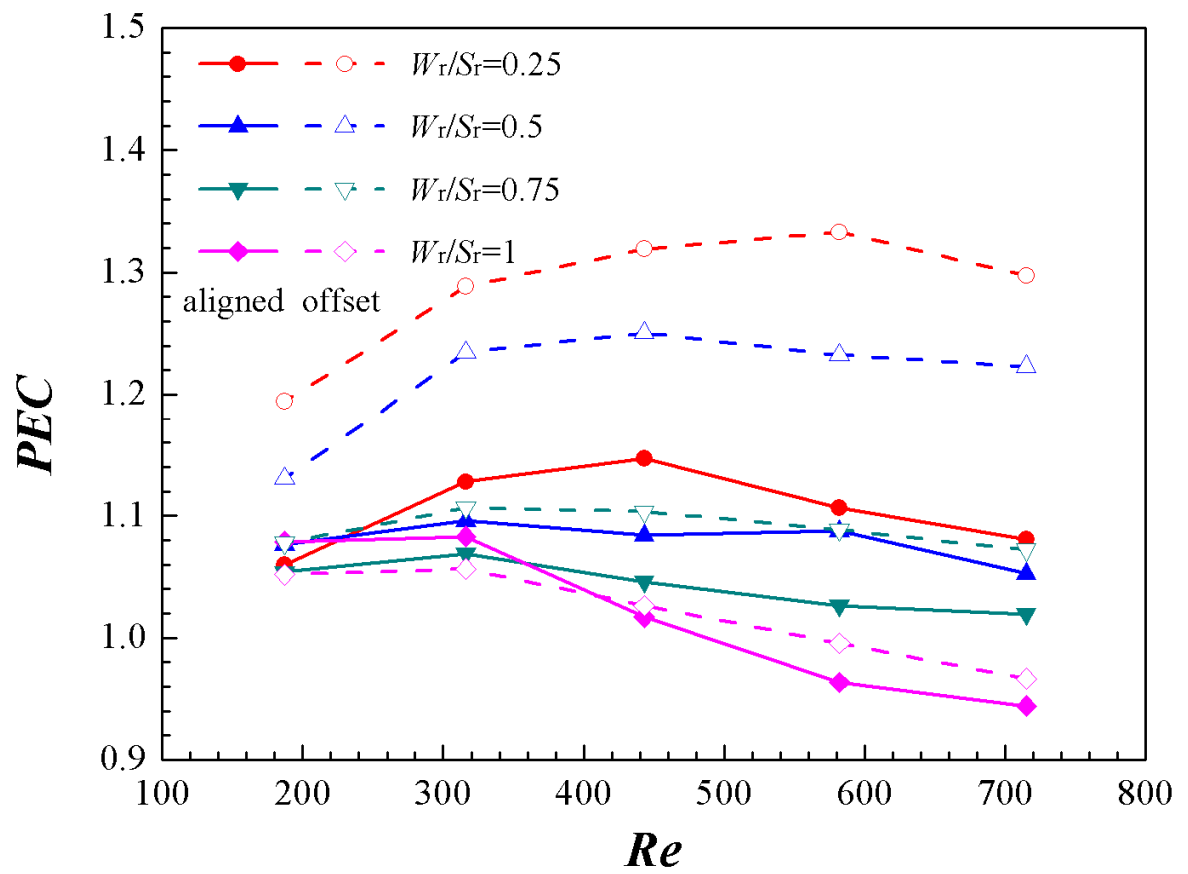

(a)

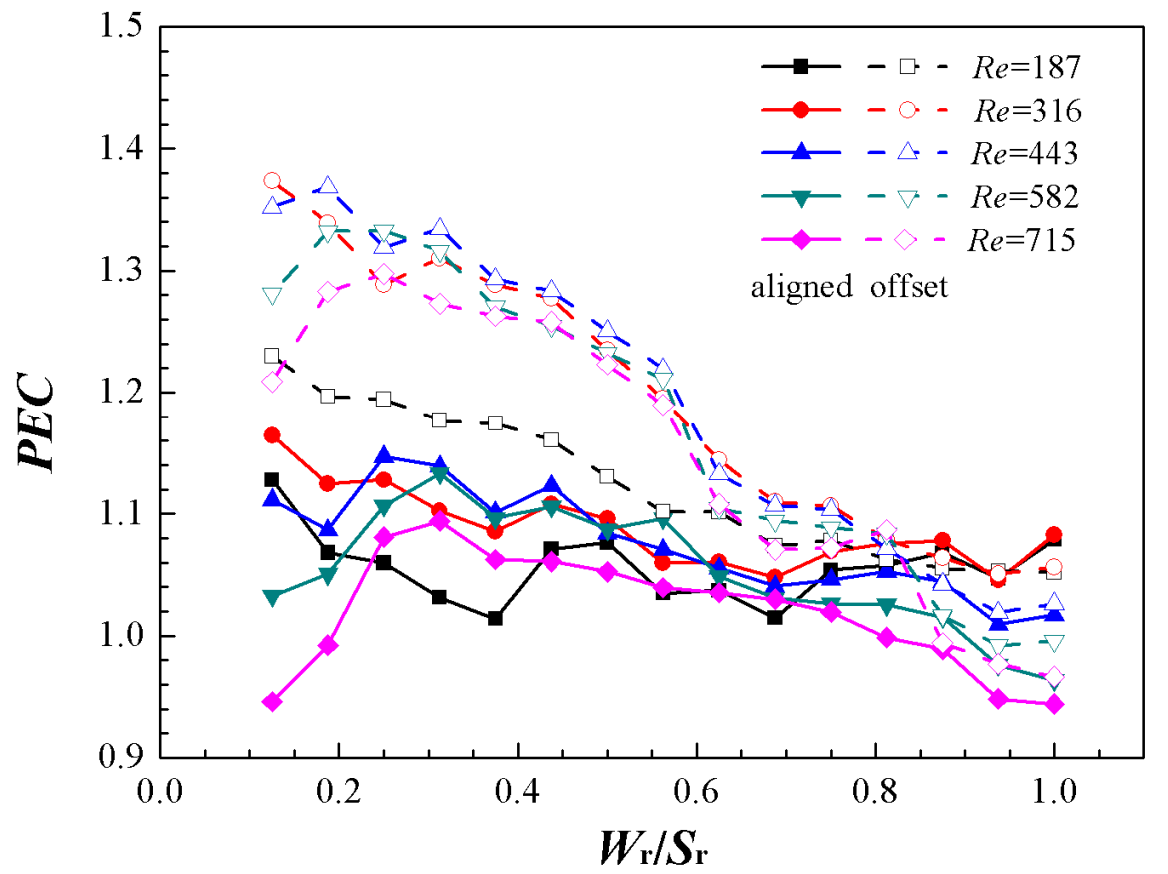

(b) 
Fig. 12

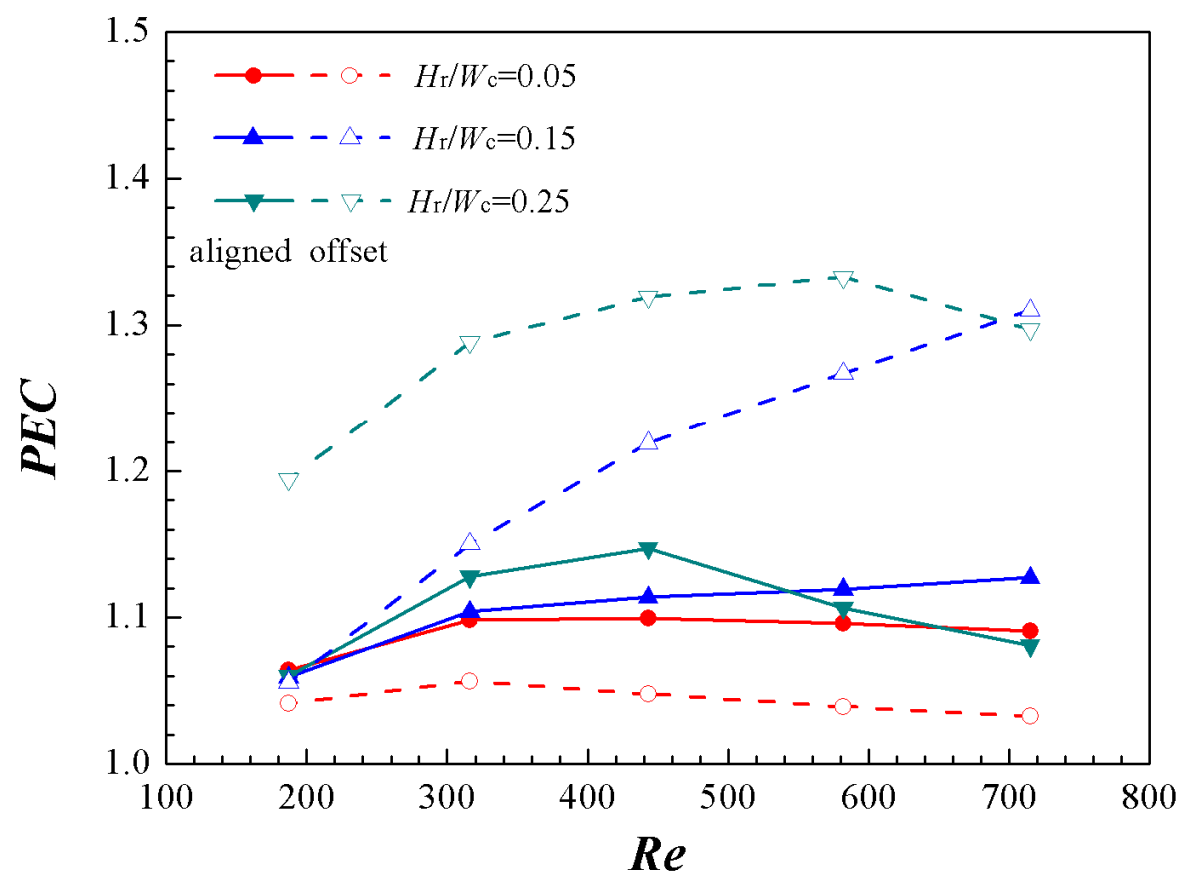

(a)

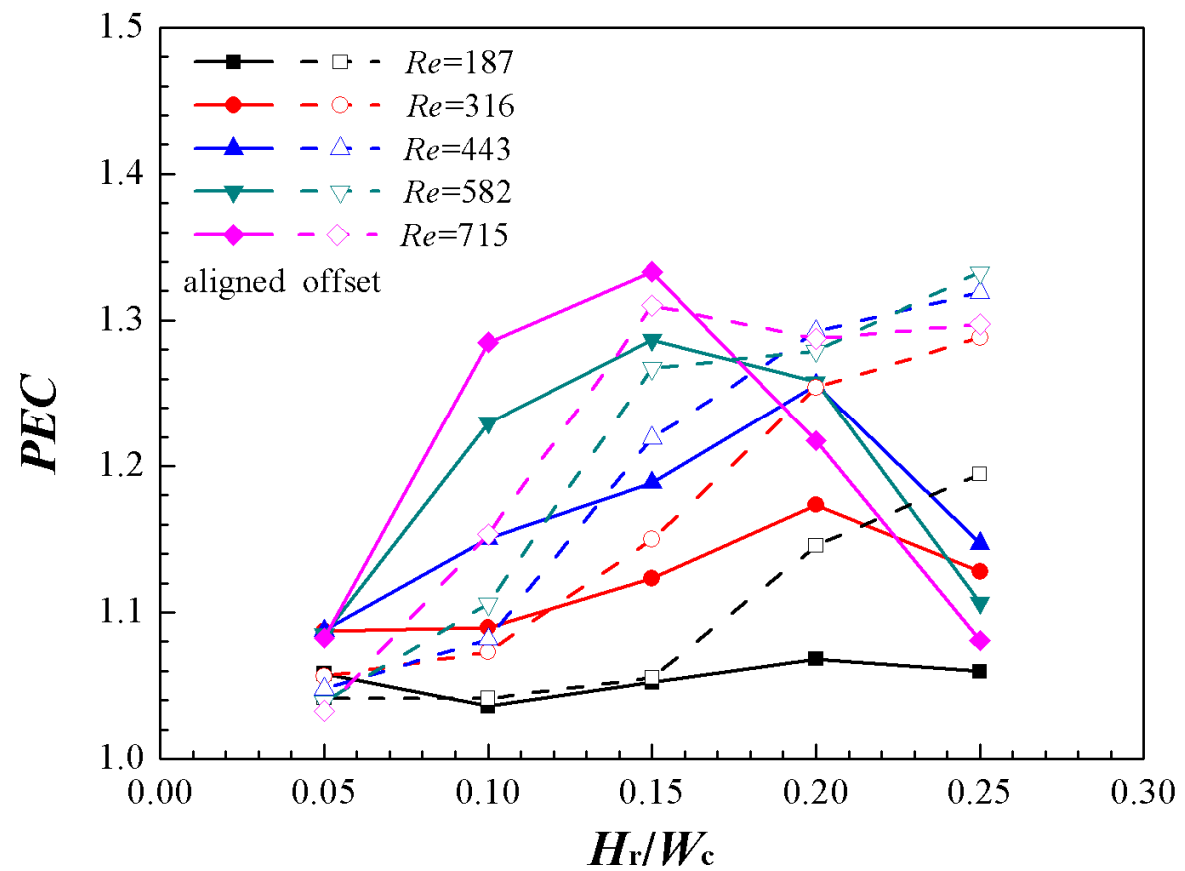

(b) 
Fig. 13

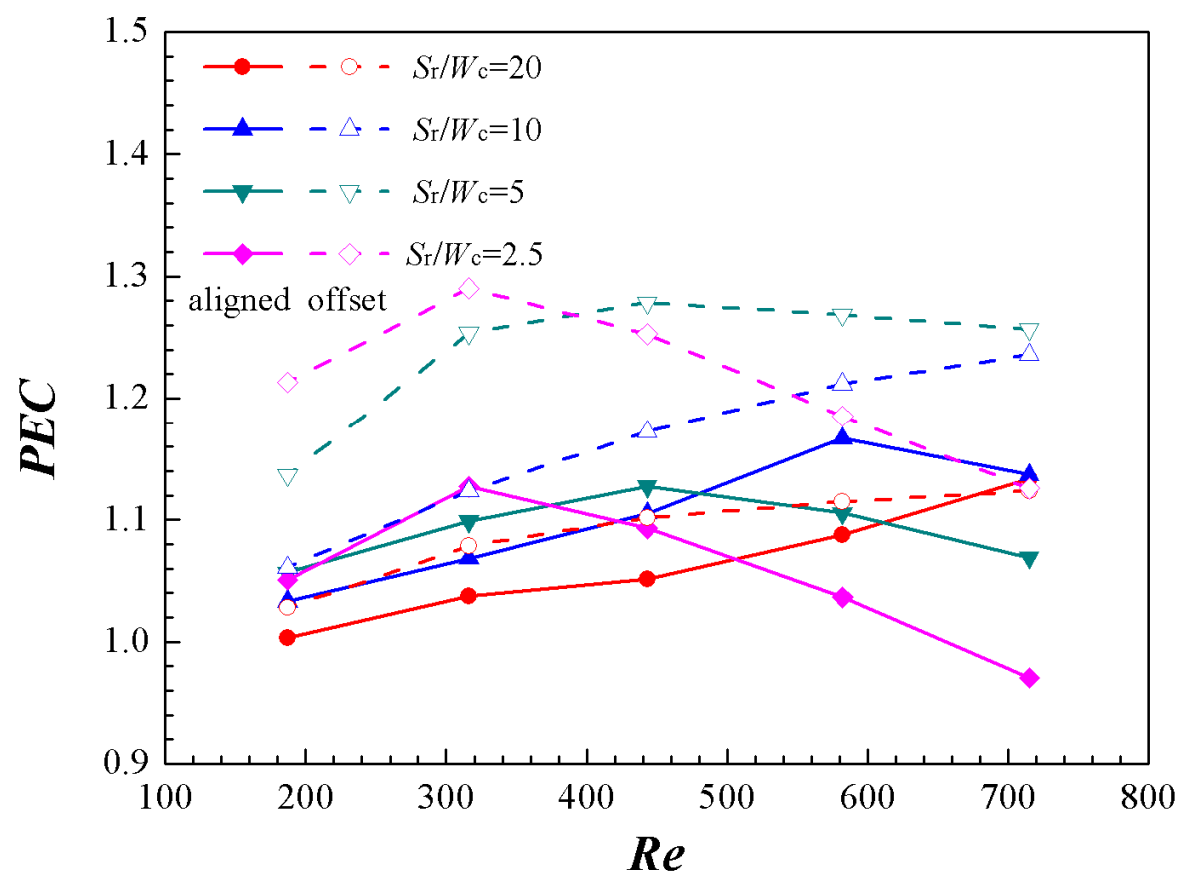

(a)

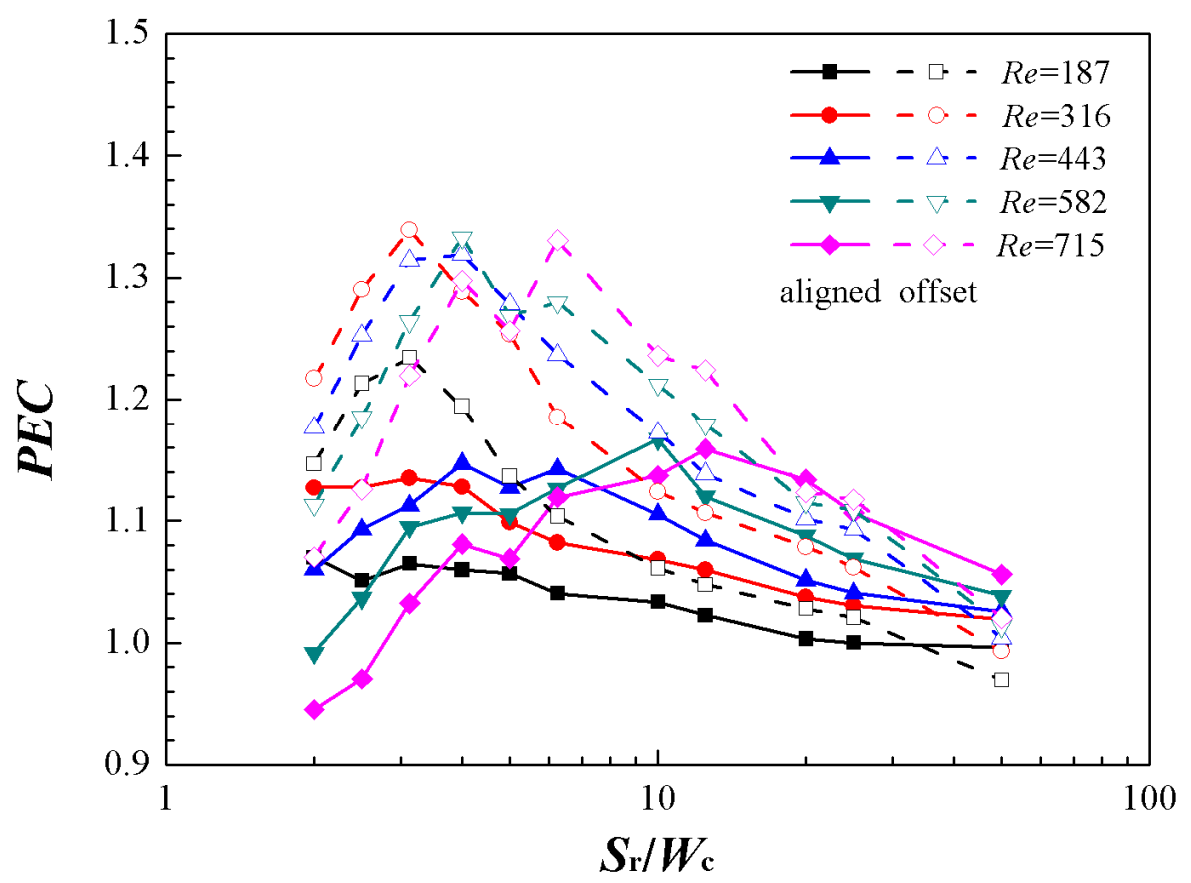

(b) 